Noname manuscript No.

(will be inserted by the editor)

\title{
Modeling Languages in Industry 4.0: An Extended Systematic Mapping Study
}

\author{
Andreas Wortmann • Olivier Barais . \\ Benoit Combemale • Manuel Wimmer
}

Received: date / Accepted: date

\begin{abstract}
Context: Industry 4.0 integrates Cyber-Physical Systems with the Internet of Things to optimize the complete value-added chain. Successfully applying Industry 4.0 requires the cooperation of various stakeholders from different domains. Domain-specific modeling languages promise to facilitate their involvement through leveraging (domain-specific) models to primary development artifacts. Objective: We aim to assess the use of modeling in Industry 4.0 through the lens of modeling languages in a broad sense. Method: Based on an extensive literature review, we updated our systematic mapping study on modeling languages and modeling techniques used in Industry 4.0 [159] to include publications until February 2018. Overall, the updated study considers 3344 candidate publications that were systematically investigated until 408 relevant publications were identified. Based on these, we developed an updated map of the research landscape on modeling languages and techniques for Industry 4.0. Results: Research on modeling languages in Industry 4.0 focuses on contributing methods to solve the challenges of digital representation and integration. To this end, languages from systems engineering and knowledge representation are applied most often but rarely combined. There also is a gap between the communities researching and applying modeling languages for In-

Andreas Wortmann

Software Engineering, RWTH Aachen University, Germany

E-mail: wortmann@se-rwth.de

Olivier Barais

University of Rennes 1, France

E-mail: Olivier.Barais@irisa.fr

Benoit Combemale

University of Toulouse, France

E-mail: benoit.combemale@irit.fr

Manuel Wimmer

Institute of Business Informatics - Software Engineering \& CDL-MINT, Johannes Kepler University Linz, Linz Austria

E-mail: manuel.wimmer@jku.at
\end{abstract}


dustry 4.0 that originates from different perspectives on modeling and related standards. Conclusions: From the vantage point of modeling, Industry 4.0 is the combination of systems engineering, with cyber-physical systems, and knowledge engineering. Research currently is splintered along topics and communities and accelerating progress demands for multi-disciplinary, integrated research efforts.

Keywords Industry $4.0 \cdot$ Modeling Languages

\section{Introduction}

Industrial revolutions always introduced step changes to manufacturing. The first industrial revolution (18th to 19th century) advanced production from manual to machine-driven manufacturing, introduced factories, and enabled leveraging steam power for production [37]. The second industrial revolution (1870 to 1914) introduced electric power to enable the mass production of goods using the concept of interchangeable parts [109]. The third industrial revolution (ca. 1980 to 2010) describes the transition from analog to digital (mostly isolated) production systems. Industry 4.0 is the fourth industrial evolution focusing on integrating digitized cyber-physical production systems with processes and stakeholders to optimize the complete value-added chain. Originally, it has been announced as part of the high-tech strategy of the German Federal Ministry for Education and Research [27]. However, the essence of Industry 4.0 has become an international phenomenon as the Japanese Industrial Value Chain Initiative [70], the Advanced Manufacturing Initiative in the United States [2], the Chinese Made in China 2025 strategy [96], Manufacturing 3.0 in South Korea [98], and the national Catapult research center on High Value Manufacturing [65] in the United Kingdom indicate.

This "fourth industrial revolution" raises new challenges for future manufacturing which are driven by four disruptions: (1) data volumes, computational power, and connectivity; (2) the emergence of analytics and businessintelligence capabilities; (3) new forms of human-machine interaction; (4) and improvements in transferring digital instructions to the physical world, such as advanced robotics and 3D printing. The interplay of these four disruptions led to recognizing four particular Industry 4.0 design principles [63]:

- Interoperability: connect production systems, devices, sensors, and people.

- Information transparency: query data and connect digital planning with the run-time data collected from sensors.

- Technical assistance: provide the right abstraction to understand the complexity of Industry 4.0 systems and processes.

- Decentralized decision making: enable autonomous systems.

All of these aim to enable more efficient production down to the individualized the mass production of "lot-size 1" [43].

Model-based software development is one of the key enablers for successfully engineering, integrating, and maintaining complex systems of systems, 
which is indicated by the increasing number of related publications in key conferences and journals investigating these challenges, e.g., see $[30,49,97,62$, $131,145]$ For successfully engineering Industry 4.0 systems of systems, fostering research in modeling is crucial to enable realizing the aforementioned design principles.

As a research area matures, there often is a significant increase in the number of related reports and results. Thus, it becomes important to summarize and to overview those results. There are different methods for structuring a scientific landscape, such as systematic literature reviews [24,77] or systematic mapping studies [117]. Systematic literature reviews are a "form of secondary study that use a well-defined methodology to identify, analyze, and interpret all available evidence related to a specific research question in a way that is unbiased and (to a degree) repeatable" [77]. They aim to summarize the existing evidence concerning the object of research (e.g., modeling languages) to identify gaps in the current research. To this end, systematic literature reviews follow an a priori defined review protocol of research questions and a documented (hence, reproducible) search strategy. Based on the obtained corpus of primary studies, the research questions are answered. Systematic literature reviews are common to software engineering $[14,59]$, model-based engineering $[25,38]$, software product lines [33,47], or domain-specific languages [53, 83], etc., while mapping studies are less common. A systematic mapping study (SMS) structures a body of research through its reports by categorizing these. These often culminate in a visual summary, the map, of its results. Such a map supports understanding what has been addressed by the community for a particular domain and its corpus can serve as the basis to answer in-depth research questions of a subsequent systematic literature review.

We investigate modeling in Industry 4.0 through the lens of modeling languages and applied to the field's diverse challenges. Conducting a systematic mapping study on modeling languages for Industry 4.0, hence, enables providing guidance and feedback for the modeling community about challenges for and reception of their contributions in the domain of Industry 4.0. Moreover, it provides an overview for the automation systems community about the contributions to modeling languages and techniques in their domain and which challenges these modeling languages and techniques address. The resulting map enables identifying limitations and challenges, as well as best practices in the field. Also, it supports identifying new lines of research and provides a corpus for future investigation.

In this paper, we present an extension of our SMS on modeling languages in Industry 4.0 presented in [159]. The previous study [159] included 1466 papers that were published until April 2017. This contribution extends its investigation with 1878 additional papers published until February 2018 to describe the use of modeling languages in Industry 4.0. Out of these, 186 additional papers were included in the resulting map. With Industry 4.0 being a multi-disciplinary, heterogeneous challenge, we consider modeling and modeling languages in a broad sense, i.e., we include 3D modeling, knowledge 
representation, business process modeling, and other modeling techniques into our study.

Following a detailed search strategy involving six digital libraries, we initially identified 3344 unique publications. Out of these, 408 publications were selected and categorized using a particular classification scheme focusing on the contribution types, research types, Industry 4.0 concerns, and modeling contributions. We present the concerns addressed by research on modeling in Industry 4.0, how these concerns are investigated, when and where the results are published, and by whom. The resulting research landscape can help to understand, guide, and compare research in this field. In particular, this paper identifies the Industry 4.0 challenges addressed by the modeling community as well as the challenges that seem to be less investigated. Through this, we obtain a classification scheme and structure the research on modeling languages and techniques for Industry 4.0. In summary, the contributions of this paper, hence, are:

- Extension of the mapping study with 1878 novel and unique primary studies published until February 2018 in Section 4

- A detailed explanation of the research method used for this extended systematic mapping study presented in Section 3.3.

- Novel investigations on modeling for cyber and physical concerns as well as on the use of standards in Section 4.3

- The discussion and investigation of trends in modeling in Industry 4.0 based on differences between the papers presented until April 2017 and the subsequently published papers in Section 5 .

- A vision on model-based DevOps for Industry 4.0 and its relation to our findings in Section 5.3.

In the following, Section 2 discusses related mapping studies and literature reviews, before Section 3 details our research method. Afterwards, Section 4 presents our findings before Section 5 reports insights into modeling in Industry 4.0 and discusses a vision of model-based DevOps for Industry 4.0 in the presence of our findings. Section 6 discusses threats to validity before Section 7 concludes.

\section{Related Studies}

Mapping studies are a common method to investigate research trends in software engineering [117]. Current studies include, e.g., the classification of techniques for test-set generation and selection [74], software development effort and cost estimation [72], the use of experimental studies [137], object-oriented design [12], the use of patterns [162], the usage of UML diagrams [123], the empirical evaluation of software requirements specification techniques [34], on software product lines [46,85], and domain-specific languages [83]. Aside from investigating different concerns, these mapping studies vary in the level of analysis detail and in the number of included publications (between 35 and 400). 
However, we found only a single mapping study on model-driven engineering [105]. That study surveys existing research on aspect-oriented modeling and code generation. However, several literature reviews and surveys focus on the Industry 4.0 domain in general.

A recent systematic literature review of Industry 4.0 related research efforts [88] discusses the state-of-the-art in Industry 4.0, deficiencies in current research, and potential research directions that culminate in a research agenda. In this context, modeling is mentioned as a frequently used technique for managing complex production systems as well as products for both: development of new artifacts and better understanding existing ones. XML, UML, and AutomationML are mentioned as frequently used modeling languages. However, a more in-depth study on the modeling aspect is not provided that review focuses on giving a general overview of Industry 4.0 literature.

Originally initiated in Germany in 2011, Industry 4.0 has attracted much attention in recent literature. In their perspective on Industry 4.0, VogelHeuser and Hess identify a set of challenges for the domain [154]. In particular, they identify four key challenges for software engineering that are well known to the modeling community:

1. Transition to modular and maintainable interfaces as a fundamental basis for adaptable and evolvable systems.

2. Tracking of changes in hundreds of heterogeneous and distributed machines or plants on different operation sites operated over decades.

3. Management while ensuring consistency of software variants and versions, including self-adaptation and reconfiguration at runtime.

4. Adaptation of big data algorithms and technologies.

Following this paper, Mosterman and Zander [110] discuss the needs and challenges of developing and operating cyber-physical systems (CPS) along with corresponding technologies to address the challenges and their potential impact. In the same trend, Turowski et al. identify the current challenges on Industry 4.0 faced by companies through a survey [80]. The survey aims to understand the stakeholders expectations, requirements and the potential challenges Industry 4.0 poses in real case studies. Complementary to these works, Trappey et al. [151] provide a consolidated review of the latest CPS literature. In this survey, they provide a complete review of international standards and an analysis of patent portfolios related to the CPS architecture model. Hermann et al. identify design principles of Industry 4.0 based on quantitative text analysis and a qualitative literature review [64]. Their paper illustrates how the identified design principles support practitioners in identifying Industry 4.0 scenarios.

A recent literature review on technologies and applications in Industry 4.0 investigated a corpus of 88 papers retrieved via Web of Science and Google Scholar [92]. In this study, the author uncovers three popular frameworks for the realization of Industry 4.0, presents key technologies (such as 5G or agentbased systems), and discusses popular applications (smart factories, smart 
products, and smart cities). Overall, that paper serves as a compact signpost guiding through a small subset of Industry 4.0 literature.

Similar studies have been conducted regarding the application and benefits of model-based software engineering in embedded systems $[4,89,150]$. The first study [89] surveyed 112 software developers from different companies on the reasons for applying model-based software engineering, its effects, and shortcomings. The authors conclude that development in embedded systems already leverages models as primary development artifacts but that adopting MBSE still is challenging and that the tools are still challenging as well.

A study on the use of UML and model-driven techniques in the design of embedded software in Brazil surveyed 209 embedded software engineers and researchers [4]. Through the study, the authors identify a lack of knowledge about the application of UML and model-based techniques due to "the lack of skills" and "the lack of coherent tools". Moreover, the authors found that modeling is mainly used for documentation whereas model-driven techniques, such as code generation, are hardly used. In contrast to this study, we investigate Industry 4.0 assuming that modeling is used. Through our search terms and exclusion criteria, we especially exclude sources not about modeling. Consequently, the research of our study differs not only on the subject but also on the focus.

However, with similar aspirations as [4], another study investigates the relevance of model-driven software engineering in the Italian industry [150]. The authors surveyed 155 Italian software professionals and inquired, inter alia challenges for the adoption of model-driven techniques, the use of code generators, interpreters, UML, and DSLs. In contrast to the results of [4] the authors uncovered that $68 \%$ of the surveyed professionals "produce models", whereas only $48 \%$ use model-driven techniques and almost all of the latter leverage code generation. Similar to the first study, they identified "easier maintenance" and "higher quality" as the main drivers for modeling. The study also finds the "typical anecdotal" challenges for adoption of modeling, such as requiring a high effort to create models and lack of supporting tools

Thus, while there is already work on summarizing the research done in the field of Industry 4.0 and related fields, none of these studies is particularly concerned with the development or application of modeling languages.

\section{Research Method}

A systematic mapping study identifies and classifies primary studies of the field under investigation. Through this, it aims to provide a systematic overview of the topics of research contributed to this area and the forms of contribution. We conducted this study following established guidelines $[77,117]$ and included useful practices and suggestions from similar studies $[26,81,83,111]$. Ultimately, we employed the five-phase process for conducting this study proposed in [117] and depicted in Figure 1: (1) Define research questions; (2) Search for primary studies; (3) Identify inclusion and exclusion criteria 


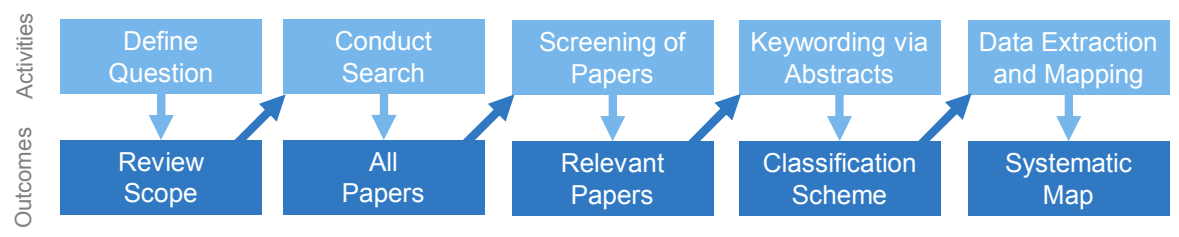

Fig. 1 The five phases of a systematic mapping study as proposed in [117].

and screen primary studies based on these criteria; (4) Classify primary studies through keywording; and (5) Extract and aggregate data.

In the first phase, we defined the scope of this study. In the second phase, we created the initial corpus of potentially relevant publications. In the third and fourth phases, we sanitized and reduced this corpus to include only relevant publications and classified according to research qualities derived from the research questions. In the fifth phase, we extracted data ${ }^{1}$ from the publications to enable answering our research questions. This section describes the activities and decisions of these phases.

\subsection{Research Questions}

We aim to identify relevant publications on development and use of modeling languages in Industry 4.0, which Industry 4.0 concerns are addressed with modeling techniques, how research addressing these concerns is conducted, and which modeling languages are used to contribute to these concerns. Moreover, we investigate who is contributing to modeling in Industry 4.0, where the contributions are published, and when they occurred. This manifests in the following research questions:

RQ1 What are the expected benefits of applying modeling languages to Industry 4.0? This question aims to uncover the high-level benefits expected by applying modeling languages to Industry 4.0.

RQ2 Which Industry 4.0 concerns are addressed through modeling languages? With this question, we investigate which concerns and challenges of Industry 4.0 are addressed through the different kinds of modeling languages.

RQ3 Which kinds of modeling languages are used in Industry 4.0 and which concerns do they address? This question investigates the use of modeling languages in Industry 4.0 and relates the findings of RQ2 to the solutions contributed to the research field.

RQ4 What are the most frequently applied research methods in the context of modeling languages for Industry 4.0? This question aims to understand how research on modeling and modeling languages in Industry 4.0 is performed and how this relates to the concerns of RQ2 and the tools of RQ3.

1 Available from companion website http://gemoc.org/modeling4Industry 4.0 / 
RQ5 Who researches modeling languages in Industry 4.0? This question investigates who has adopted this notion and contributes to modeling in Industry 4.0.

RQ6 Where have the contributions been published? Similar to the RQ5, we like to uncover which venues are relevant to publishing on modeling for Industry 4.0.

RQ7 When did the contributions on modeling languages to Industry 4.0 occur? With this question, we investigate when modeling started contributing to smart manufacturing.

To answer these questions, we conducted the literature search presented in the next section.

\subsection{Search Strategy and Data Sources}

The search strategy guides the identification of relevant publications to answer the research questions. This includes conceiving an appropriate search query and identifying relevant libraries to apply this clause to. Industry 4.0 , at its core, focuses on manufacturing, production processes, and ultimately the "factory of the future" $[54,142]$ or the "smart factory" $[86,120]$. Thus, in contrast to [92], we included these terms in our search clause. Similarly, the second part of our search clause focuses on the objects of modeling research, its modeling language technology, instead of specific modeling languages. Thus, we search for publications mentioning metamodels, DSLs, modeling languages, or UML as relevant contributions to modeling in our context. This ultimately leads to the logical search clause depicted in Figure 2.

("digital factory" OR "digital factories" OR "smart factory" OR "smart factories" OR "factory of the future" OR "factories of the future" OR "Industry 4.0") AND ("metamodel" OR "DSL" OR "UML" OR "domain-specific language" OR "modeling language" OR "modelling language")

Fig. 2 Logical search clause defined to identify relevant literature.

Essentially, this is a conjunction of two disjunctions: The first part of the conjunction captures terms related to Industry 4.0. The second part captures terms representing the objects of modeling research. As we conducted a fulltext search with this clause, we omitted including synonyms for "DSL" or "modeling language". Papers contributing to modeling should at least use these terms in either related work or the referenced literature. Although we cannot exclude omitting a small number of possibly relevant publications that do not provide such discussions, searching this way yields better results than just searching titles and abstracts. Moreover, we also did not enforce any inferior year-limit and included papers published until February 2018. Where such complex logical conditions were not supported, we searched for parts 


\begin{tabular}{llr}
\hline Digital Library & URL & Papers \\
\hline ACM Digital Library & https://dl.acm.org & 138 \\
Google Scholar & https://scholar.google.com & 3133 \\
IEEE Xplore & https://ieeexplore.iee.org & 255 \\
Scopus & https://www.scopus.com/ & 504 \\
SpringerLink & https://link.springer.com & 342 \\
Web of Science & https://www.webofknowledge.com & 32 \\
\hline Total (incl. duplicates) & & 4404 \\
\hline
\end{tabular}

Table 1 Search results returned from the different digital libraries.

of the query and joined the results manually. For ACM Digital Library we could reuse the query as is (modulo minor changes to its concrete syntax). For Google Scholar we used its advanced search mode to separate to split the query into five queries, each containing one exact phrase of the modeling terms (i.e., "modeling language", "metamodel", etc.) and at least one of the domain terms (i.e., "Industry 4.0", "digital factory", etc.). We extracted the results using Harzing's Publish or Perish ${ }^{2}$ software to extract results. Due to its limitation to ca. 1.000 citations per query, we downloaded the citations in multiple parts using inferior and superior year limits. We manually merged the resulting lists of citations and removed the Scholar-internal duplicates obtained by our process manually. Through this, we aim to minimize the issues of using Google Scholar for structured literature retrieval [22] (e.g., non-commutativity of logical disjunctions) while benefiting from its wealth of provided publications.

IEEE Xplore enforces a limit of 40 search terms, which did not affect our query and supports the use of nested Boolean queries through its advanced search, hence data retrieval was straightforward. Similarly, retrieving citations from Scopus, SpringerLink, and Web of Science did not require any changes to the query as all three libraries support nested Boolean queries through their advanced search. Applying our query - with the explained operative modifications - to ACM Digital Library, Google Scholar, IEEE Xplore, Scopus, SpringerLink, and Web of Science yields the results presented in Table 1.

Due to including Google Scholar, this search includes documents unsuitable to answer our research questions, such as non-peer reviewed publications, descriptions of curricula, or patents. These were removed in the next phases as illustrated in Figure 3: First, we removed 1060 duplicate documents from the results, then we applied the criteria for inclusion and exclusion to remove additional 1369 documents based on their title, keywords, and abstracts in the screening phase (Section 3.3). Afterwards, the results contain 1975 peerreviewed, English, possibly relevant papers. We reviewed each of these papers during the classification phase (Section 3.4) to understand whether these are relevant to our study and applied the criteria for inclusion and exclusion to the complete paper. In total, 408 papers remain in our corpus. The next sections detail our criteria for inclusion and exclusion as applied in the screening phase as well as in the classification phase.

2 Publish or Perish: https://harzing.com/resources/publish-or-perish 


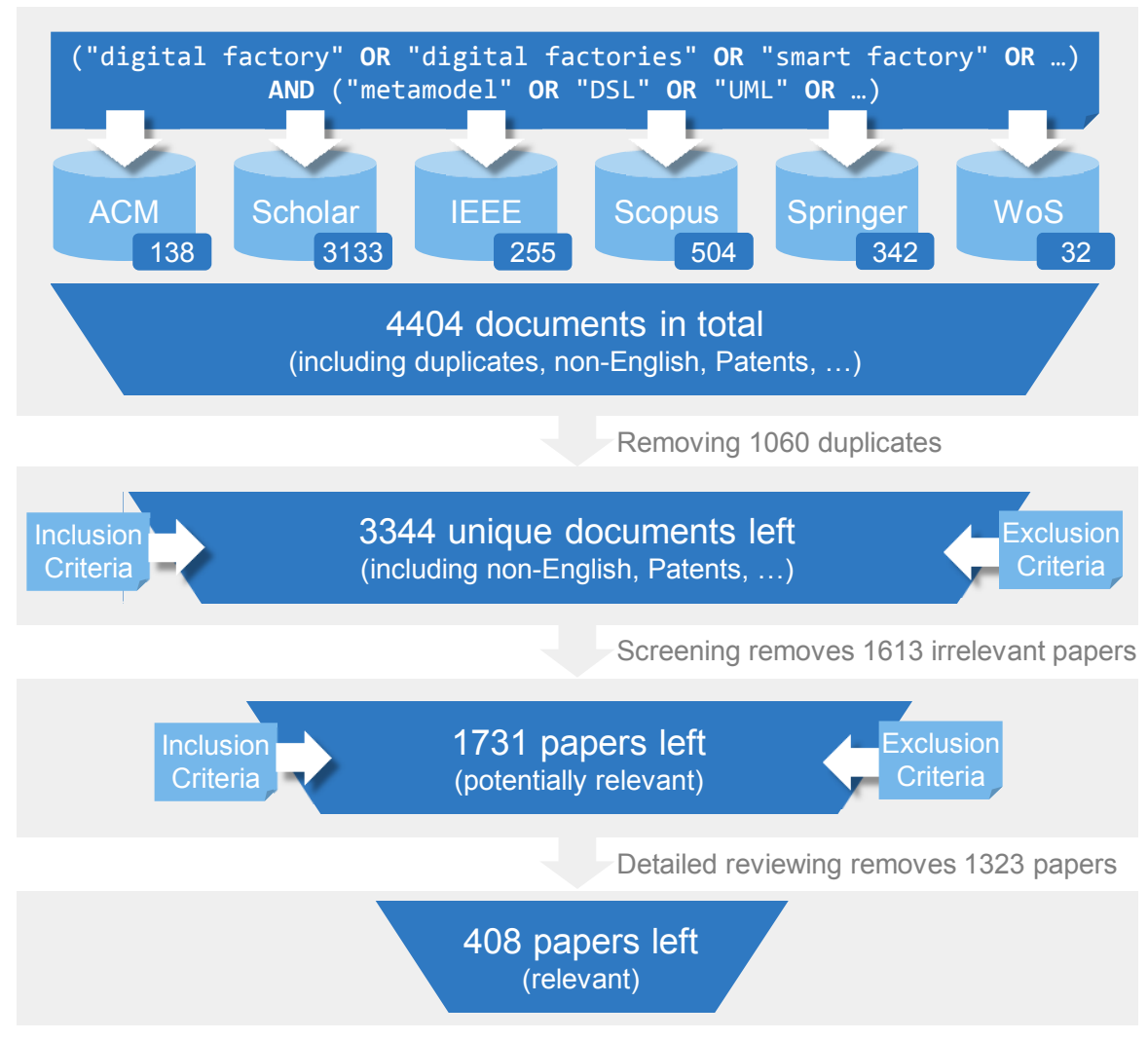

Fig. 3 Data collection initially produced 3344 unique documents, out of which 408 were identified as relevant for our study.

\subsection{Screening Papers for Inclusion and Exclusion}

The inclusion of a study into the classification phase of a systematic mapping study usually is decided on its title, abstract, and keywords. To reduce the corpus and enable reproduction of the study, we established the following inclusion criteria and exclusion criteria.

Inclusion Criteria: We identified potentially relevant documents based on the following three criteria:

1. Peer-reviewed studies published in journals, conferences, and workshops.

2. Studies are accessible electronically.

3. From title, abstract, and keywords we can deduce that the paper focuses on developing or applying modeling languages in Industry 4.0.

Exclusion Criteria: Documents fulfilling the inclusion criteria may still be excluded based on the following four criteria: 
1. Studies not available in English.

2. Studies not systematically peer-reviewed, such as books, slides, websites.

3. Teasers and short papers of less than two pages, such as calls for papers, editorials, or curricula.

4. Studies where Industry 4.0 is mentioned as a future application, related work, or broad context only, e.g., papers on the Internet of Things (IoT) or CPS mentioning Industry 4.0 as a possible use case only.

To align our understanding of Industry 4.0 and the classification scheme, each of the authors reviewed the first 20 (about $1 \%$ ) documents of the corpus of 3344 unique documents on his own. We discussed results and built a shared understanding of the documents as well as of our methodology and goals. As a next step, the remaining 3324 documents were filtered by the first author based on the unambiguous criteria of being non-English, non-peer reviewed, or teasers only.

Removing 1593 documents left 1731 papers for review. These were split into three corpora of 430 papers and one corpus of 441 papers, which were reviewed and classified by a single author each. To continuously align our shared understanding of the topic and our classification scheme, inclusion, exclusion, and classification were discussed among the authors in bi-weekly teleconference sessions. During these, we excluded additional publications and refined our shared understanding of the classification scheme. We did, however, not discard papers based on their comprehensibility or venue alone. We also assigned each paper to the most suitable research type facet to yield a clear partitioning of the data set according to the categories in Table 3. Where the author reading a paper was uncertain about its inclusion or classification, we discussed this paper also among all authors. To prevent classification fatigue, we performed classification in blocks of at most one hour broken up by at least 15-minute breaks.

We then applied the criteria to titles, keywords, and abstracts. Where this did not suffice to determine inclusion, we temporarily included the publications for the classification phase to prevent excluding relevant, but suboptimally phrased publications. In that phase, the final inclusion or exclusion could be decided based on the publication's full text. Hence, this phase only eliminates publications obviously not within our study's scope and publications failing on formal requirements (such as not being available in English). In detail, we eliminated 1060 duplicates as well as 1369 publications outside this study's scope, including non-peer reviewed publications (e.g., theses, technical reports, websites, patents, project deliverables, etc.), non-English publications, full proceedings (Google Scholar produces complete conference proceedings as results), and teasers (publications of two pages or less). Publications in languages other than English were excluded for this reason alone. Concurring with [82], we did not conduct any additional quality evaluation, such as including papers published at highly ranked conferences or workshops only. Hence, after the screening phase, 1975 potentially relevant papers remain in the corpus. 


\subsection{Classifying Studies}

In the classification phase, we reviewed the remaining 1975 papers to assign qualities of the dimensions derived from the research questions. To this end, we followed [117] in considering at least the introduction and the conclusion. However, for almost all most papers this was insufficient and we read the complete paper for proper classification. This also is the last phase in which publications were eliminated. Hence, after further elimination of 1567 irrelevant papers, a total of 408 publications remained. We classified these papers along the facets described in the following.

\section{Contribution Type Facet}

The first facet is inspired by [117] and classifies publications according to the type of research they contribute (RQ4). We adapted this to our study by employing the five contribution types presented in Table 2. These contribution types are disjoint and each paper was classified to provide exactly one contribution type. When a paper was suitable for more than one contribution type, we discussed this and assigned the most suitable contribution type.

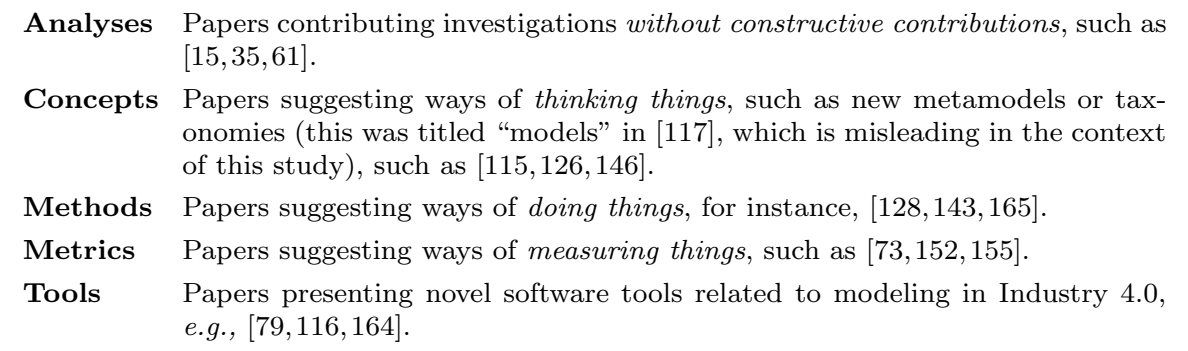

Table 2 Contribution type facets inspired by [117] and adjusted to our research questions and corpus.

Research Type Facet

Also inspired by [117], we classified the publications according to the research type they contribute. This enables addressing RQ4 regarding the most frequently applied research methods contributed to modeling in Industry 4.0. Again, we adjusted these also to better fit to our study. In particular, we eliminated the category of philosophical papers as such papers did not occur. The resulting, disjoint, research types are depicted in Table 3. Each paper was classified to belong to exactly one research type. Papers suitable for more than one research type were discussed and assigned the most suitable research type. 
Evaluation Papers evaluating existing techniques, e.g., [36,50,161].

Experience Report of personal experiences, such as [18,19].

Solution A novel solution is presented and argued for with case studies, for instance $[28,40,119]$.

Validation Papers presenting novel techniques and experimenting with them, such as $[57,132,163])$.

Vision Non-disruptive research agendas, such as the vision of model-based logistics engineering presented in $[8,69,93]$.

Table 3 Research type facets also inspired by [117] and adjusted to our research questions and corpus as well.

\section{Industry 4.0 Concern Facet}

We also classified the publications along the Industry 4.0 concerns addressed by the various publications. This addresses RQ2 and aims to uncover which concerns are investigated how often. During classification, keywording ( $c f .[117]$ ) the abstracts, introductions, conclusions, and, if necessary, of the complete paper, we produced the following Industry 4.0 concerns. In contrast to contribution types and research types, these concerns are not disjoint and included papers can contribute to multiple concerns.

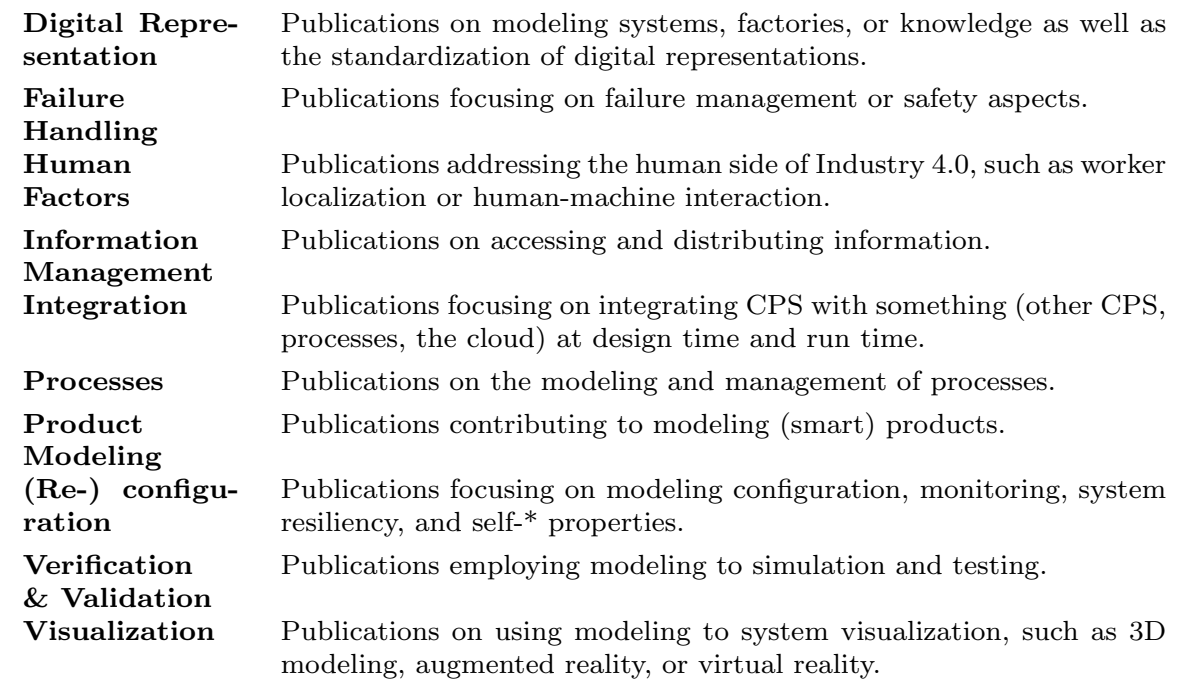

Table 4 Industry 4.0 concern facets defined for the corpus of 408 papers. 


\section{Modeling Technique Facet}

To find answers to RQ3 regarding the modeling tools and languages used in Industry 4.0, we also classified the publications along this dimension. Overall, we found various modeling techniques (e.g., different CAD tools, UML dialects, DSLs, knowledge representation languages, etc.) and many papers addressed more than one modeling technique. To prevent dissipating the results we sorted the modeling techniques into groups (such as 3D modeling, architecture description languages, or business process modeling techniques) and isolated modeling techniques specific to Industry 4.0 (such as AutomationML). This produced the 15 groups presented in Table 5 .

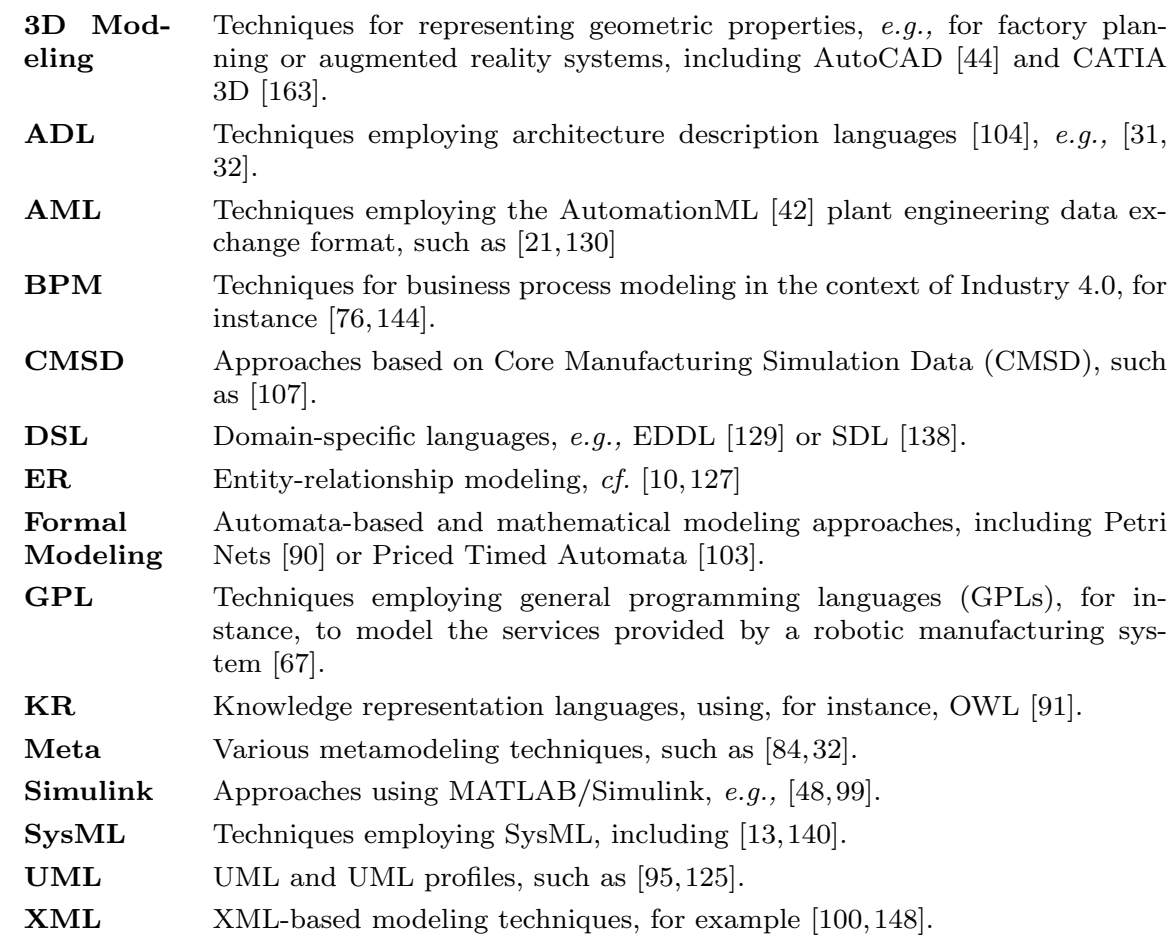

Table 5 Modeling language facets.

Moreover, we also investigated whether the included publications report on real-world industrial applications. Out of the 408 included publications, only $23(5.64 \%)$ reported such applications. The industrial domains include automotive [39,68,79], avionics manufacturing [121,127], packaging [155], production of white goods [9], oil production [71,133], and production of windows and doors [7]. The next section presents our main findings along the four classification dimensions. 


\section{Findings}

This section presents our findings on the expected benefits of applying modeling languages to Industry 4.0 as well as on the contribution types, research types, Industry 4.0 concerns, and modeling concerns for the included papers.

\subsection{Expectations on the Impact of Modeling Languages on Industry 4.0}

With RQ1 ("What are the expected benefits of applying modeling languages to Industry 4.0?"), we address the expected impact of contributing research in modeling to Industry 4.0 challenges. To this effect, we extracted these expectations whenever these were made explicit. Out of the 408 publications included after classification, only $55(13.48 \%)$ papers explicitly described the authors' expectations on the impact of their contribution. The expectations include reducing the cost of production system integration [52], saving energy on production system reconfiguration [103], and remaining internationally competitive in high-wage countries [143]. We classified the expectations into expectations on

- reducing time (development time, time-to-market),

- reducing costs (of development, integration, (re-)configuration),

- improving sustainability, and

- improving international competitiveness.

Overall, the included publications explicated 59 expectations. Out of these, most publications expected modeling to either reduce cost (26x mentioned) or time $(22 \mathrm{x})$. Only a few publications propose modeling to improve sustainability $(4 \mathrm{x})$, increase international competitiveness $(3 \mathrm{x})$, to facilitate learning $(2 \mathrm{x})$, or to enhance the quality of products $(2 \mathrm{x})$. However, as the number of papers making the expectations of contributing modeling in Industry 4.0 explicit is rather small, these motivations cannot be generalized.

\subsection{Industry 4.0 Concerns Addressed with Modeling Languages}

With RQ2 ("Which Industry 4.0 concerns are addressed through modeling languages?"), we investigate which concerns of Industry 4.0 are addressed using modeling techniques and how they are addressed in terms of contribution types (Table 2) and research methods (Table 3 ).

Investigating this, we found that most publications on modeling in Industry 4.0 contribute methods to challenges in digital representation (considered by 120 publications), integration (113), and processes (73). Out of the 614 concerns addressed by the included publications, these three combinations of contribution types and concerns make up $49.84 \%$ of concerns addressed by papers of our corpus. Overall, the majority of contributions are methods $(69.71$ $\%$ ) or concepts $(13.52 \%)$ whereas tools $(9.61 \%)$, analyses $(6.68 \%)$, or metrics $(0.49 \%)$ are contributed significantly less often. 


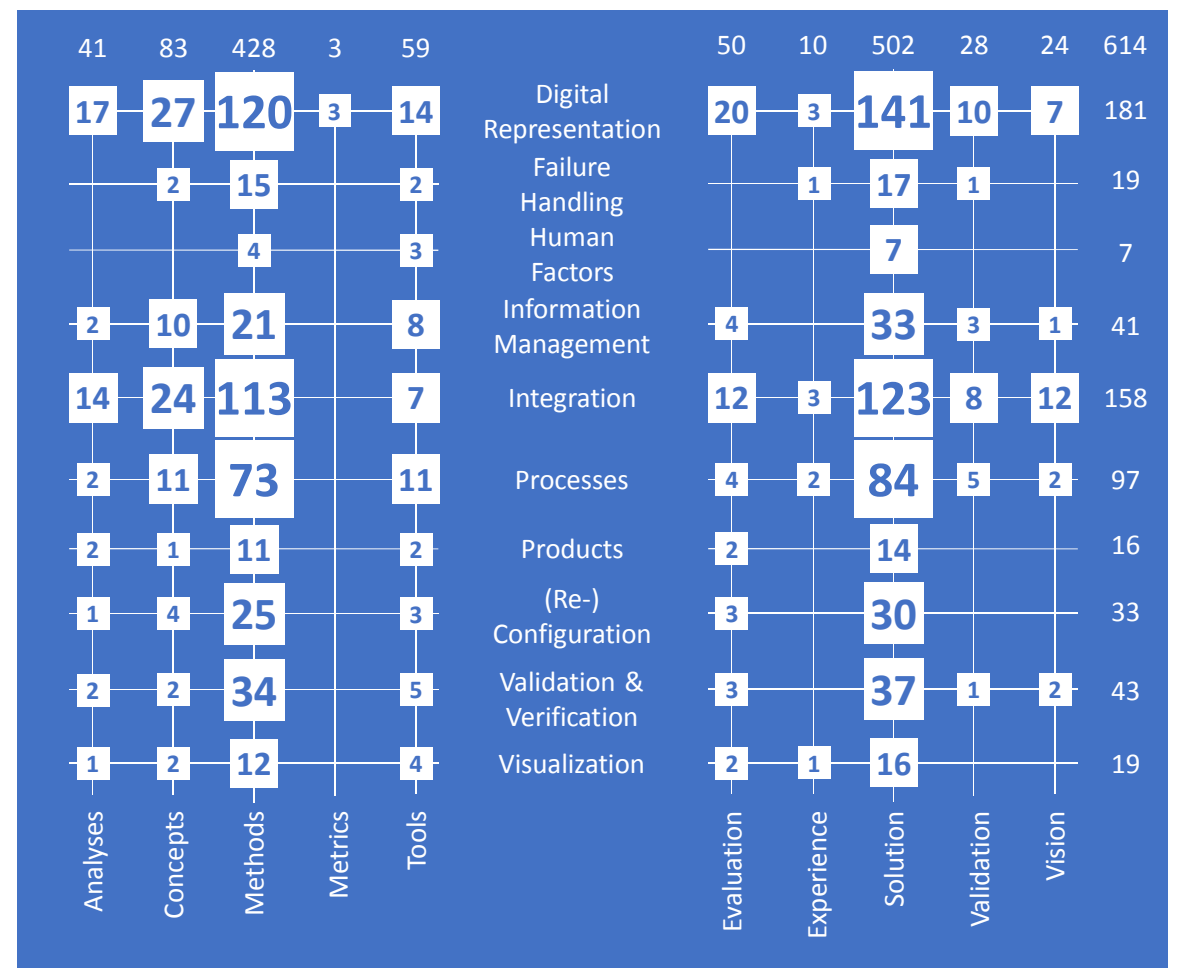

Fig. 4 Industry 4.0 concerns by research type and contribution type.

With contributions claiming to reduce costs and time ( $c f$. Section 4.1), the lack of papers contributing metrics to track these claims is surprising. However, the new papers included after April 2017 do not investigate metrics at all. The results concerning contribution types - as inquired by RQ4 ("What are the most frequently applied research methods in the context of modeling languages for Industry 4.0?") - are depicted on the left part of Figure 4 and these findings are reflected by the research type contributions on its right part. Most contributions are solution proposals (i.e., application of existing techniques to solve particular problems) that focus either on digital representation or on integration challenges. It is also surprising, that only a few publications investigate modeling for the (smart) product, which is supposed to control its production processes in many visions of Industry 4.0.

With respect to the publications' research types, we found that solution proposals make up $123.04 \%$ of the publications. These also most often address digital representation (addressed in 141 publications), integration (123), and processes (84). Out of the 614 concerns addressed by the publications included in our corpus, these three combinations of research types and concerns make up $49.84 \%$ of addressed concerns. 


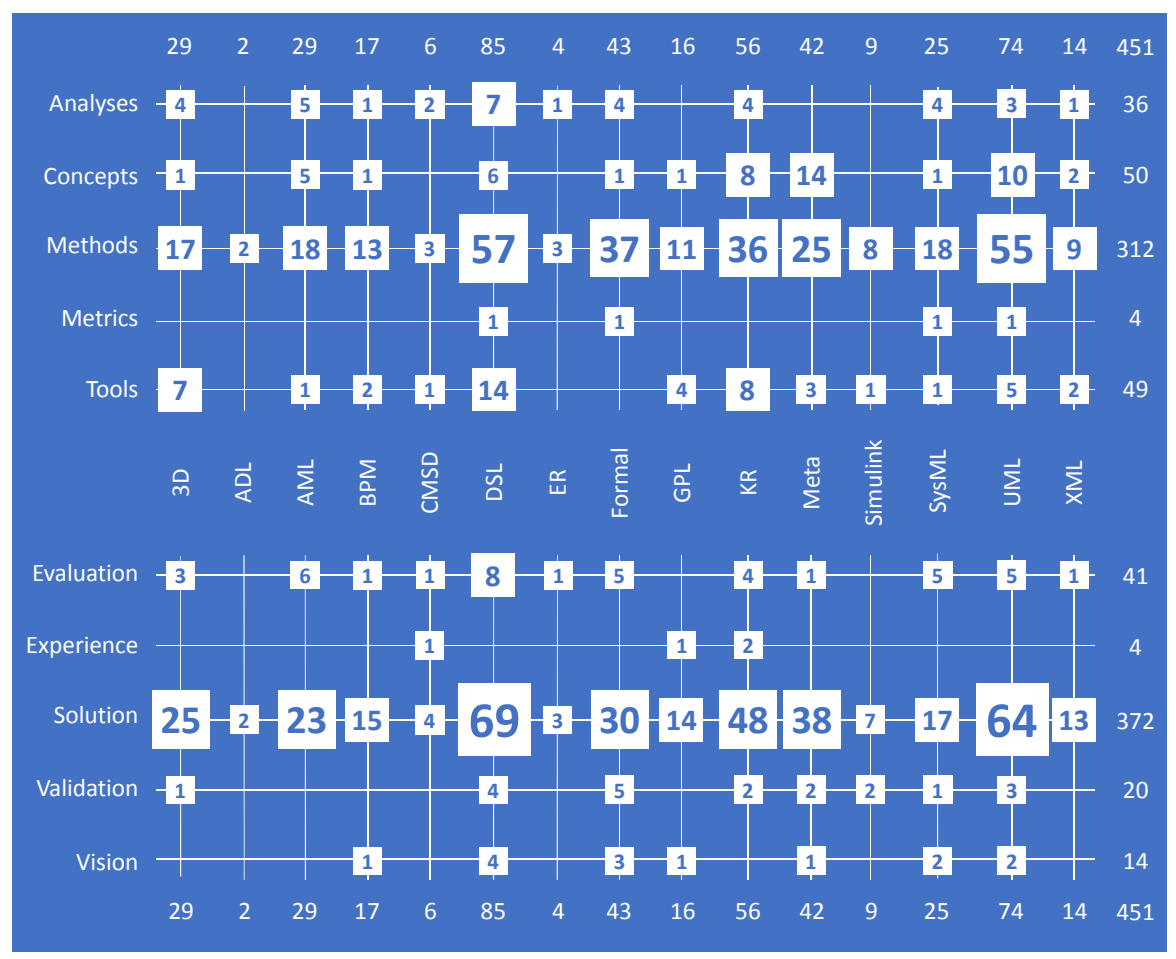

Fig. 5 Modeling language facet by research type and contribution type.

Other research contributions are significantly less common. Evaluation reports contribute only $12.25 \%$ of the included papers, validation papers only $6.86 \%$, vision papers only $5.88 \%$, and experience reports only $2.45 \%$ of the included papers are contributed significantly less often. That most solution papers also are method papers might reflect the very constructive research typical to modeling. However, the large number of method papers over papers contributing new concepts, validating new techniques, or proposing visions implies that research mainly approaches Industry 4.0 with established methods and techniques. This is supported by our findings on the modeling techniques contributed to Industry 4.0 presented in the next section.

Moreover, we investigated whether research on modeling languages in Industry 4.0 focuses more on the cyber (i.e., software) elements of automation or on its physical elements. To this end, we noted whether the publications explicitly mention which kind of parts the contributions are applied to. We found that $252(61.76 \%)$ explicate this. They provide contributions focusing on cyber elements, physical elements, activities, or a combination thereof. Overall, 59 (14.46\%) publications focus solely on cyber elements, 36 (8.82\%) focus solely on physical elements, and $29(7.11 \%)$ focus on activities that are not specified whether being cyber or physical. Of the remaining publications, $106(25.98 \%)$ focus on cyber-physical elements, $10(2.45 \%)$ on purely phys- 
ical activities, and $12(2.94 \%)$ on activities incorporating cyber and physical elements.

While research on modeling languages for Industry 4.0 is very balanced between contributing to handling cyber elements and physical elements, modeling physical elements or processes operating with them is important to modeling in Industry 4.0 .

\subsection{Modeling Languages Applied to Industry 4.0}

Regarding RQ3 ("Which kinds of modeling languages are used in Industry 4.0 and which concerns do they address?"), out of the 408 publications included in our classification, a total of $86(86.03 \%)$ publications explicitly specified the (meta)modeling technique the authors applied to Industry 4.0. Examining these publications produced 124 different modeling techniques. Most notably among these are:

- Variants of UML, such as DiSpa [17], Mechatronic UML [136], UMM [101], and UML4IoT [149];

- The systems modeling language (SysML) [147] and its variants, such as SysML4Mechatronics [48] and SysML4Modelica [20];

- Knowledge representation techniques, mostly employing the Web Ontology Language (OWL) $[60,112]$ or the Semantic Web Rule Language (SWRL) [66, 131].

- Metamodels specific to Industry 4.0 challenges, such as the industrial metamodel for automation systems [108] or AutomationML [84].

- Metamodeling techniques, such as ADOxx [45,156], MetaEdit+ [31,32], or Xtext [55,78].

- Various DSLs, such as the EXPRESS DSL for product data modeling [40], the virtual factory data model [75], the Industry 4.0 process modeling language [118], the graphical modeling language for value networks [135], or the graphical modeling framework for production processes [94].

Overall, out of the 408 classified papers, 85 (20.83\%) contribute or apply DSLs to specific to Industry 4.0 challenges and total of $74(18.14 \%)$ papers employ UML (including variants) We also observed that leveraging UML and DSLs is not mutually exclusive in Industry 4.0 as 8 of the publications, such as $[6,56,141]$, employ both. A total of $74(18.14 \%)$ papers employ knowledge representation techniques, $29(7.11 \%)$ papers use AutomationML [42], and $25(6.13 \%)$ papers use SysML to address Industry 4.0 challenges. We also found $42(10.29 \%)$ publications that discuss some form of conceptual metamodeling, i.e., describing the entities and their relations, of a specific aspect of Industry 4.0. Out of these only eight papers explicitly identified the metamodeling techniques used to define software languages for Industry 4.0 challenges. These either employed language workbenches, such as Xtext $[78,106,114]$ or MetaEdit+ [31,32], or generic metamodeling frameworks, such as MOF [86], and Ecore [84]. Overall, $127(31.13 \%)$ of the overall contributions address Industry 4.0 challenges with new DSLs or metamodeling techniques. This could 


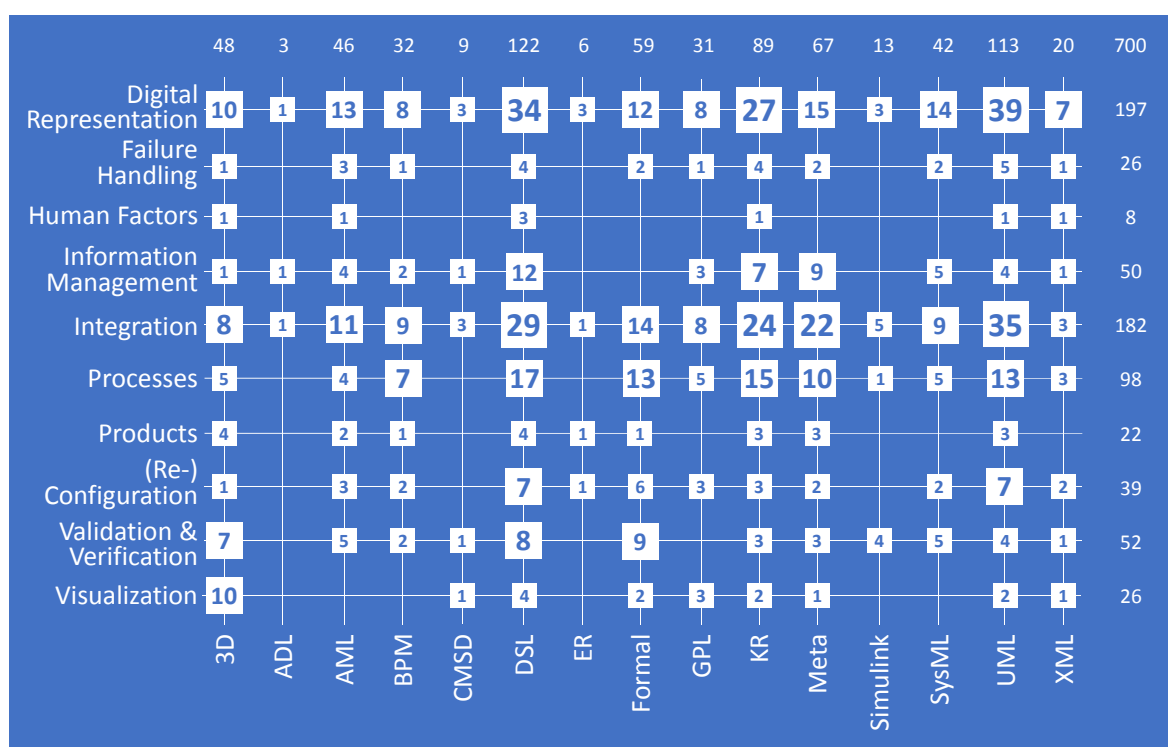

Fig. 6 Individual Industry 4.0 concerns and modeling techniques addressing these.

hint at modeling challenges that cannot be properly addressed by established modeling techniques.

To answer RQ3, we also investigate which modeling languages are applied to address the different Industry 4.0 concerns. The results, depicted in Figure 6, show that UML is used mostly to solve challenges in digital representation (39 publications) and integration (35 publications), which is consistent with identifying these as the most important challenges addressed by included publications. Consequently, these also are the two concerns most often addressed with knowledge representation techniques, DSLs, SysML, and AutomationML as well. For process modeling, another important aspect if Industry 4.0, DSLs are most popular (17 publications), followed by the application of knowledge representation techniques (35) publications), formal methods (13) publications), and UML (also 13) publications)

Overall, the concerns digital representation and integration - addressed by either AutomationML, various DSLs, knowledge representation techniques, SysML, or UML - represent $33.43 \%$ of the 700 concerns addressed with modeling languages. Together, these are a major focus of the field's research activities. While the usage of UML and DSLs is almost equally distributed between both concerns, knowledge representation techniques lean towards digital representation challenges.

The results also show that neither validation \& verification, nor the human factors crucial to the success of Industry 4.0 or product modeling are investigated as much as integration and digital representation. Whereas the former might require solving digital representation and integration (to some degree) first, the lack of research on the latter two is elusive. Unless the smart factory 
of the future is fully automated, human interaction and control are necessary and should be considered appropriately.

We also observe that standards are crucial bases on shared understanding in the context of Industry 4.0. And while many papers apply techniques implementing standards to Industry 4.0, out of the 408 papers, $66(5.64 \%)$ papers explicitly discuss, relate to, or challenge 54 different standards defined by the International Organization for Standardization (ISO), the American National Standards Institute (ANSI), the International Electrotechnical Commission (IEC), the Simulation Interoperability Standards Organization (SISO), the American Society of Mechanical Engineers (ASME), and the National Institute of Standards and Technology (NIST). The standards are addressed in the context concerns identified as research contributions of the corpus, including digital representation, human factors, integration, metamodeling, processes, and visualization. But they also address cross-cutting concerns, such as the environment, quality issues, safety, and security.

With integration being one of the Industry 4.0 concerns investigated most often, the most popular standards regarding modeling for Industry 4.0 also focus on integration as well. The standard for the exchange of product model data ("STEP", ISO 10303) is considered most often and discussed 12 times. It is followed by the standard for the integration of life-cycle data for process plants including oil and gas production facilities (ISO 15926), which is mentioned 9 times, and the standard on enterprise-control system integration, mentioned 7 times (IEC 62264). The standard defining a data model for computerized numerical controllers ("STEP-NC", ISO/TS 14649) also was mentioned 5 times. Other standards discussed at least once in the context of integration include the standards on data element types with associated classification scheme (IEC 61630), the parts library standard ("PLIB", IEC 13584), Core Manufacturing Simulation Data ("CMSD", SISO-STD-008), manufacturing message specification ("MMS", ISO 9506), industrial manufacturing management data ("MANDATE", ISO 15531), metadata registries (ISO/IEC 11179), or the metamodel framework for interoperability (ISO/IEC 19763). Overall, integration is the main driver for the standardization of modeling techniques in Industry 4.0.

Other important drivers for discussing, challenging, or relating to standards are (1) processes and process modeling which is addressed by the standards ANSI/ISA-88, ISO/DIS 18828-5, IEC 61499, ISO 22400, ISO 60848, ISO 6983, ISO/IEC 19510, and ISO/IEC 6523; (2) digital representation in the context the standards IEC 61346, ASME B5.59-2, ISO 42010, ISO/IEC 10746 ISO/IEC 14662, and ISO/IEC 19501; and (3) visualization with the related standards ISO 10628, ISO 15519, ISO 3511, ISO 1219, ISO/PAS 17506, ISO 14306, ISO 14739. Overall, this indicates that standardization is in line with the general research direction in the field.

Out of the 54 standards, at least 13 standards address topics of direct interest for the modeling community in software engineering, as these directly specify, imply, require, or constrain (meta) modeling techniques. These include standards prominent in software engineering, such as Unified Modeling Lan- 


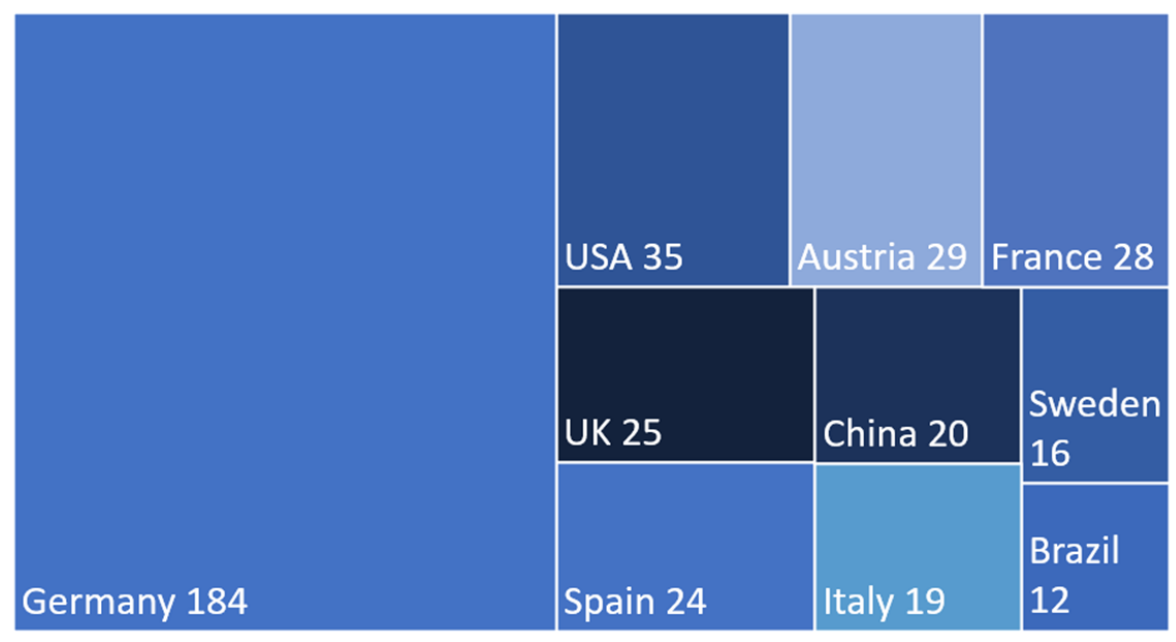

Fig. 7 The 10 most actively publishing countries with authors contributing to modeling in Industry 4.0 are largely from Europe and contribute $82.91 \%$ of the publications.

guage (UML) in version 1.3 (ISO/IEC 19501), the Business Process Model and Notation (BPMN, ISO/IEC 19510), or the Meta Object Facility (MOF, ISO/IEC 19502), or architecture description (ISO/IEC 42010). The majority of modeling-related standards in Industry 4.0, however, appear to be less prominent in the modeling community in software engineering. We assume that this indicates a gap between both communities, modeling in automation systems engineering and modeling in software engineering.

\subsection{Countries and Institutions Contributing to the Field}

Investigating RQ5 ("Who researches modeling languages in Industry 4.0?"), we found that $184(45.1 \%)$ of the publications were contributed by teams including German authors, followed by teams including authors from the USA (35 publications), Austria (29 publications), and France (28 publications) as depicted in Figure 7. Overall 53 countries contributed to research on modeling languages for Industry 4.0 in 521 contributions (papers with authors from multiple countries count as multiple country contributions). Out of these, the 10 most actively publishing countries produce 392 (75.24 \%) Among these 392 contributions, $325(82.91 \%)$ contributions are from Europe. This suggests that modeling in Industry 4.0 still largely is a European research project despite starting related initiatives in many countries across the globe.

Aside from the contributing authors' countries, we also identified the institutions most actively engaging in research on modeling languages for Industry 4.0. Overall 358 institutions contribute to the field. Due to Industry 4.0 being coined in Germany and $45.1 \%$ of the included publications having German co-authors, it is unsurprising that out of the 10 most active institutions in this 


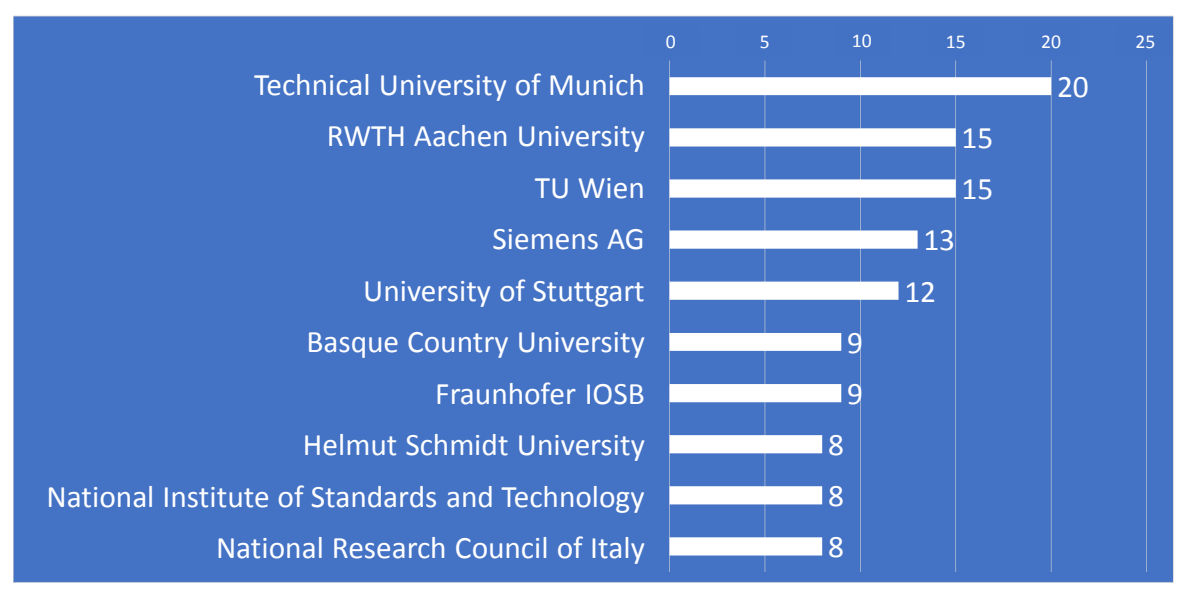

Fig. 8 The 10 most active institutions engaging in research on modeling for Industry 4.0.

field, 6 are from Germany (as depicted in Figure 8). It is, however, interesting that among these most active institutions are two national research institutions, the USA's National Institute of Standards and Technology (NIST) and the National Research Council of Italy, whereas for Austria, Germany, and Spain the most active institutions are universities or companies. Multi-national institutions were assigned the country of their headquarter.

Out of the 358 overall contributing institutions, 235 (65.64\%) are universities, $72(20.11 \%)$ are companies, and $51(14.25 \%)$ are other kinds of research institutes, such as the Department of Energy of the USA, the Greek ATHENA Research and Innovation Centre, or the German Fraunhofer institutes. While this might indicate that - despite being a business-driven paradigm ( $c f$. Section 4.1) - research on modeling in Industry 4.0 could be driven by academic researchers, our initial data collection also produced 235 (7.03\% out of the 3344 potentially relevant unique publications) patents via Google Scholar. These indicate that there is industrially driven research on Industry 4.0 that does not necessarily lead to scientific publications.

4.5 Popular Venues for Publications on Modeling Languages for Industry 4.0

Regarding RQ6 ("Where have the contributions been published?"), we found that most papers are published at conferences $(249,61.03 \%)$, followed by journals $(137,33.58 \%)$, and workshops $(22,5.39 \%)$. We also identified the most popular journals, conferences, and workshops of this particular field of research, to answer RQ6 on the most popular venues for modeling research in the context of Industry 4.0 .

Figure 9 presents the 10 most popular journals, where $(15.26 \%)$ of the related journal papers are published. Where journals produced the same number of publications, they are represented in alphabetical order according to 


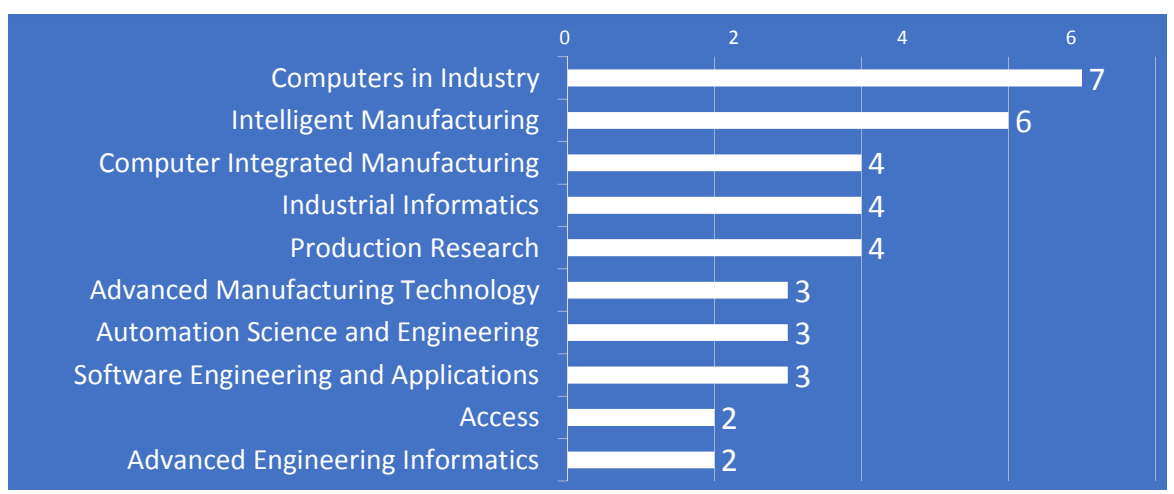

Fig. 9 Most popular journals for publications on modeling for Industry 4.0.

their name. Notably, no publications of the Transactions on Industrial Informatics (no. 4) or the International Journal of Production Research (no. 5) were included in the dataset until April 2017. However, the small numbers of publications in these most popular journals, do not support conclusions over their importance. As the Industry 4.0 matures, future studies maybe could draw such conclusions based on larger corpora of relevant publications.

The 10 most popular conferences regarding modeling in Industry 4.0, depicted in Figure 10, publish, with $38.15 \%$, also a large part of the related conference publications. Again, conferences yielding the same number of publications are represented in alphabetical order according to their full name. The large number of conference publications supports the conclusion that the conference on Emerging Technologies and Factory Automation (ETFA) - publishing $31(12.45 \%)$ of included conference papers - is the most important conference for publications on modeling in Industry 4.0. The nine other most popular conferences published between 4 and 15 papers on the topic. With some distance to ETFA, the International Conference on Industrial Informatics (INDIN), the CIRP Conference on Manufacturing Systems (CIRP CMS), and the conference of the IEEE Industrial Electronics Society (IECON) are the next most popular conferences for modeling in Industry 4.0. Together, they publish a similar share $(14.05 \%)$ of related papers.

Overall, the 10 most popular journals and conferences publish $32.6 \%$ of the included papers, which hints at a healthy distribution of publications over multiple venues. This is reflected by the 22 workshop papers included in the classification, which were published at 20 different workshops. In this context, no trends on workshop popularity can be observed.

\subsection{Publication Activities over Time}

Regarding RQ7 ("When did the contributions on modeling languages to Industry 4.0 occur?"), we found that modeling for Industry 4.0 was already 


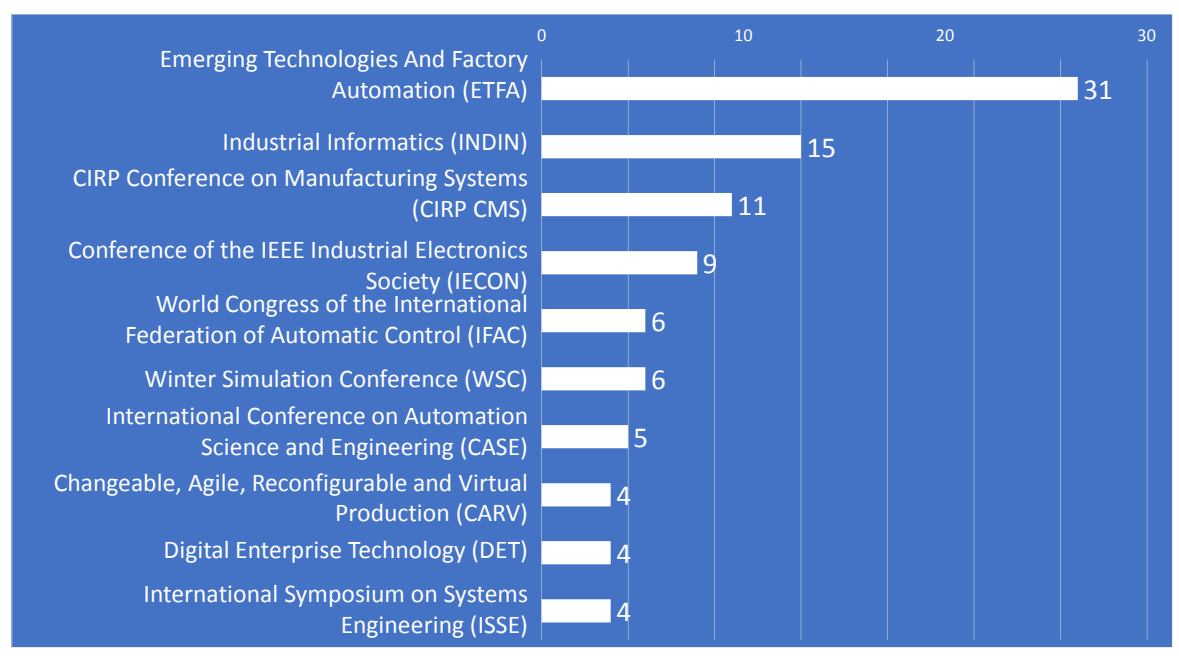

Fig. 10 Most popular conferences for publications on modeling for Industry 4.0.

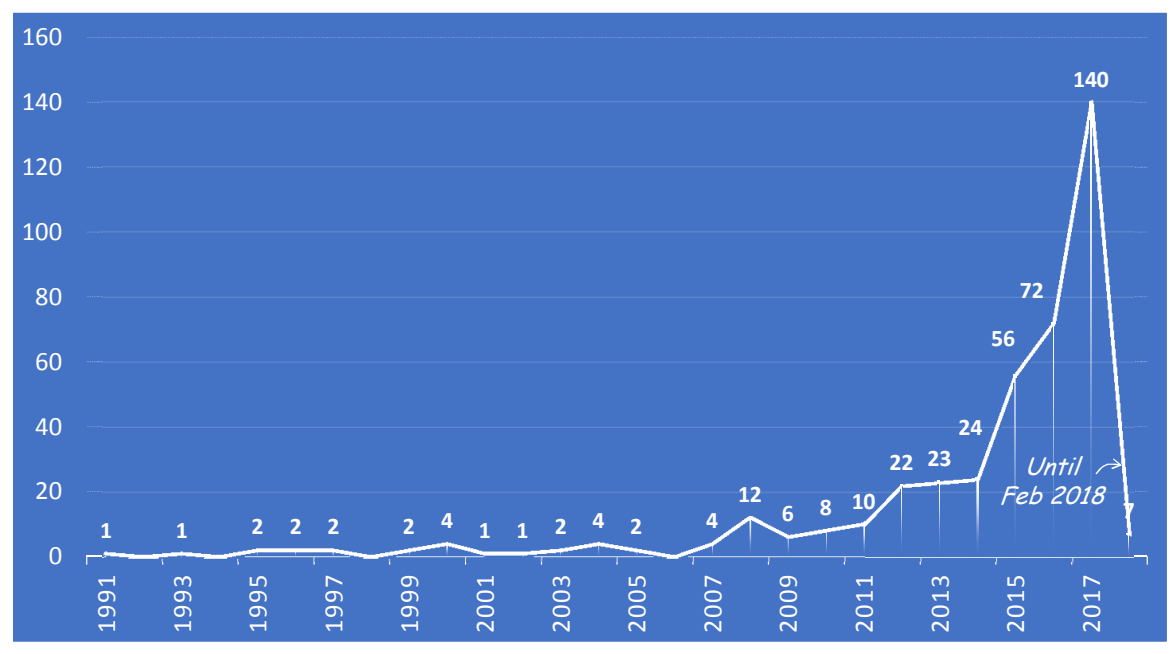

Fig. 11 Number of publications per year until February 2018 (missing numbers identify years without related publications).

addressed as early as 1991 [158], although the term "Industry 4.0" was not coined yet. Over half $(219,84.56 \%)$ of related publications were published starting in 2016 and 345 (84.56\%) of the publications are from 2011 (the year the term "Industry 4.0" was coined) or later ( $c f$. Figure 11) and later. We also observe that the number of papers increased by $(31.82 \%)$ on average per year since 2011. Whether this trend will continue requires future investigation. 


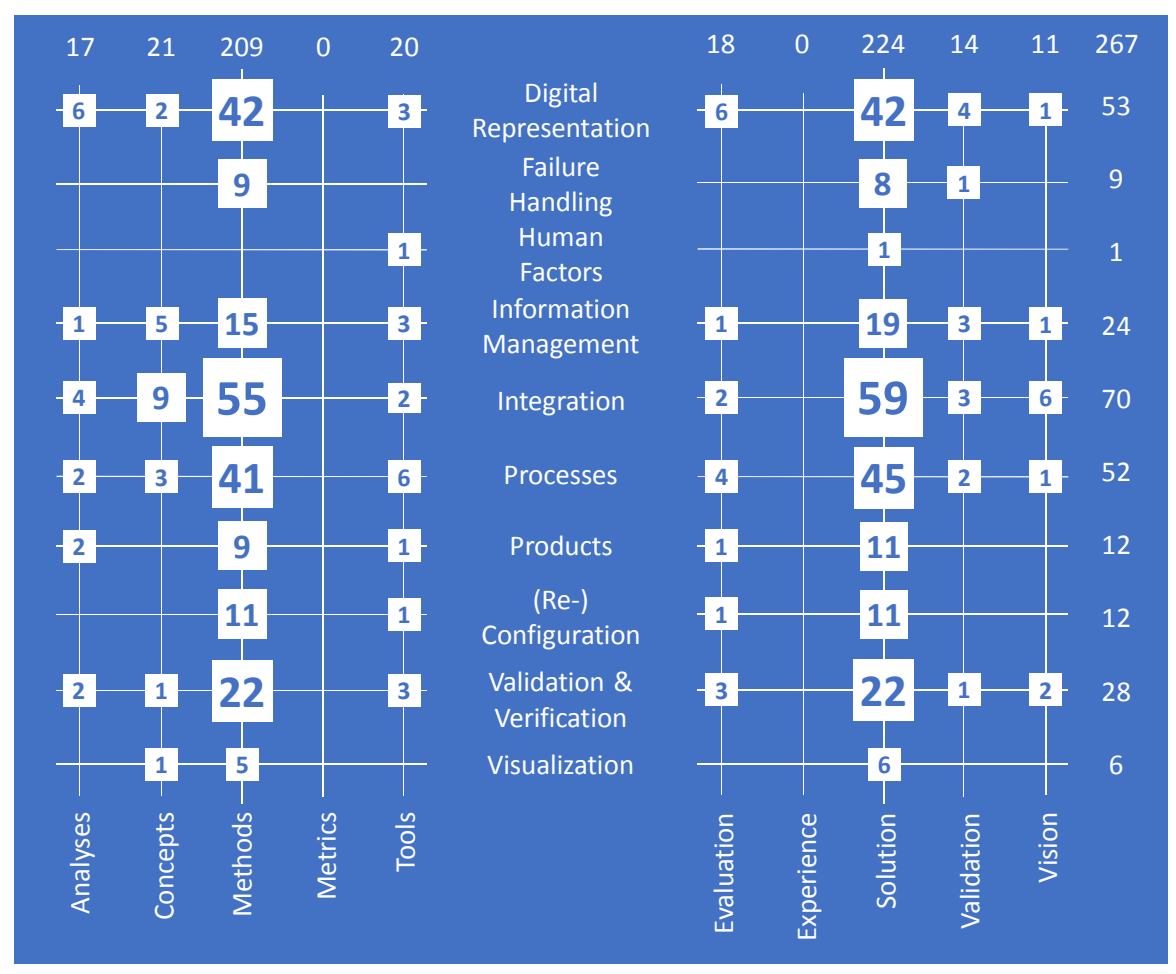

Fig. 12 Numbers of addressed Industry 4.0 concerns relative to the different contribution types and research types contributed by the 186 publications included since April 2017.

\section{Trends and Perspectives on Modeling for Industry 4.0}

Updating our previous mapping study provided the unique opportunity to investigate publication trends between April 2017 and February 2018. While we are aware of this compact time frame, comparing both data sets produced interesting observations. Subsequently, this section presents perspectives on potential future trends of research in modeling for Industry 4.0.

\subsection{Trends in Modeling for Industry 4.0}

We extended the mapping study with papers published between April 2017 and February 2018. Through this, we included 186 (an increase of $83.78 \%$ ) additional papers into our observations, which corresponds to the increase of addressed concerns of $76.94 \%$. Comparing both data sets yields insights into differences between publications until April 2017 and afterwards.

Considering changes in contribution types with respect to addressed Industry 4.0 concerns, we found significant increases regarding methods (450\%) for product modeling, validation and verification $(183.33 \%)$, and failure handling 


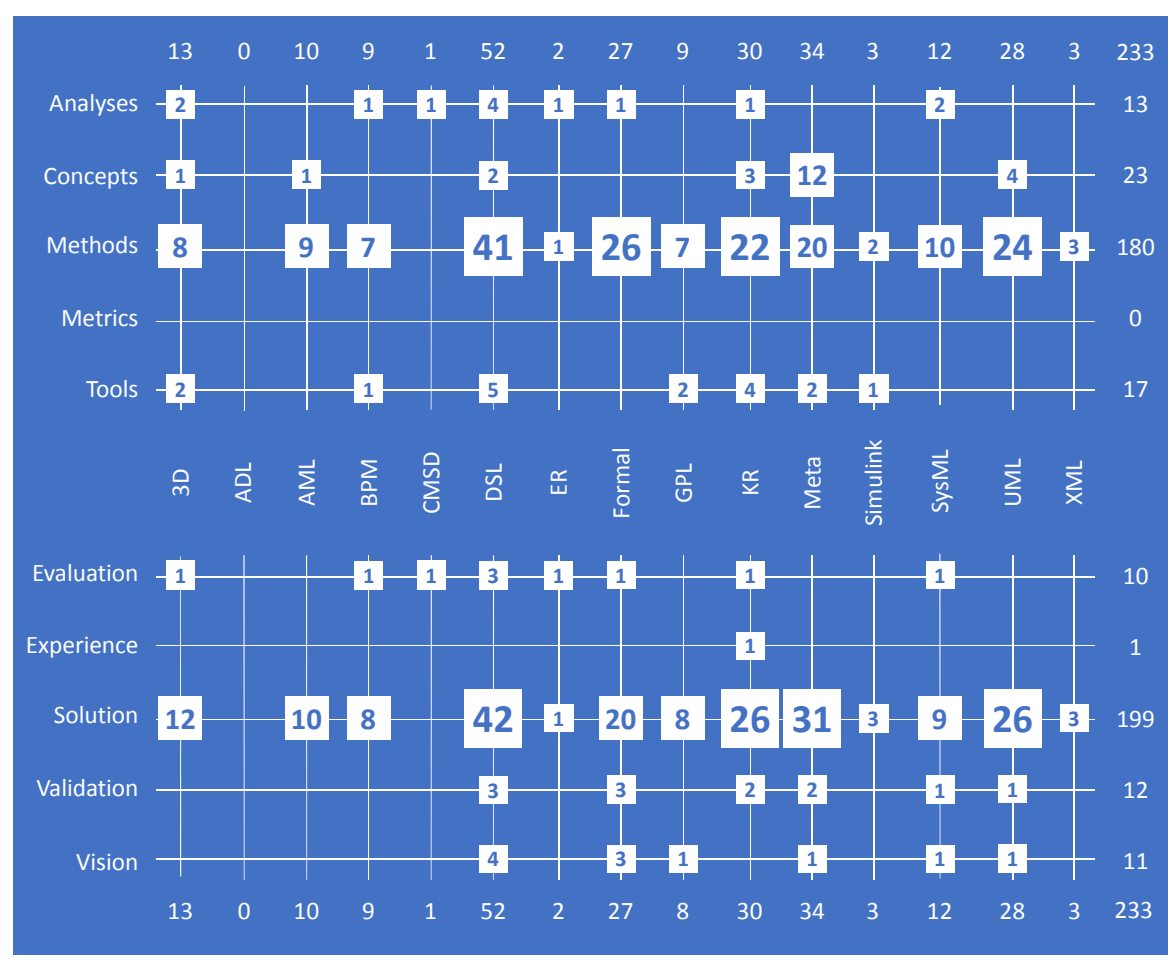

Fig. 13 Numbers of applied modeling techniques relative to the different contribution types and research types contributed by the 186 publications included since April 2017.

(150 \%), as well as regarding tools for validation \& verification (150\%). Concerning the research types of the publications in the updated corpus, we found that solutions for product modeling $(183.37 \%)$, for validation \& verification $(146.67 \%)$, and for information management $(135.67 \%)$ increased the most. The absolute numbers of increases regarding contribution types and research types are depicted in Figure 12.

Nonetheless, we also found that analyses (54.55\%), methods (53.85\%), tools $(27.27 \%)$ for digital representation showed a disproportionately lower increase. This might indicate that some techniques for digital representation have become a stable basis for other research to build upon. Overall, contributions investigating product modeling (300\%), validation \& verification (186.67\%), and information management $(135.7 \%)$ increased the most. This change of focus from digital representation and integration, as found in [159], to validation \& verification and processes could be in line with building on top of established representation and integration techniques.

Regarding the technologies addressed by the included publications, we found that, relatively, the use of metamodeling techniques (425\%), formal methods (169\%), and domain-specific languages (158\%) for Industry 4.0 increased the most. This could be an effect of a wave of early approaches in- 


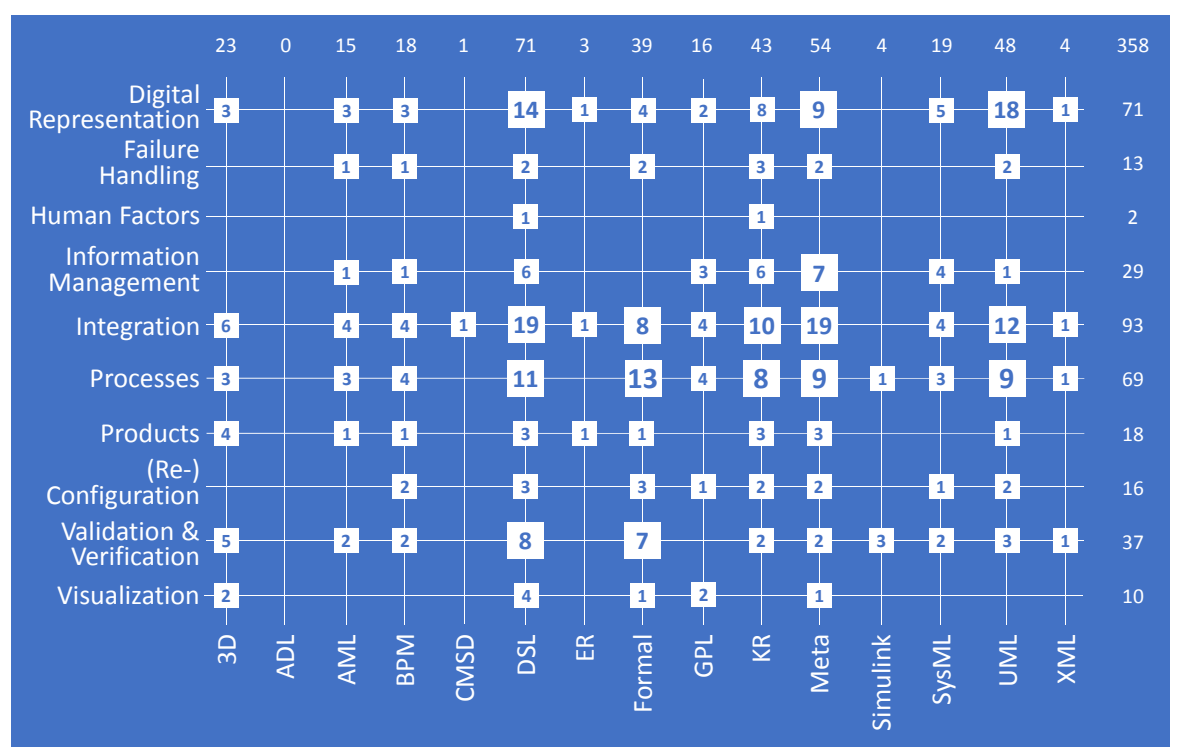

Fig. 14 Numbers of Industry 4.0 concerns addressed by the different modeling techniques as contributed by the 186 publications included since April 2017.

vestigating applying more general or established modeling techniques, based, e.g., on UML or XML [159], abating. Moreover, this underlines the importance of modeling knowledge in Industry 4.0.

In contrast, the use of pure XML or Simulink increased by $27 \%$ and 50 $\%$, respectively, only. However, with their absolute numbers - as presented in Figure 13 - of publications considering pure XML or Simulink being low to begin with, their relative small increases might not imply any trends.

Investigating trends regarding modeling techniques applied to Industry 4.0 concerns, we found that the application of the different metamodeling techniques to processes $(800 \%)$ and integration $(633 \%)$, as well as the application of knowledge representation techniques to information management (600\%) increased the most. In contrast, the overall application of ADLs (0\%) and CMSD (13\%), XML (25\%), Simulink (44\%), and AutomationML (48\%) increased the least. However, the low number of publications on metamodeling found initially [159] explains their relatively sharp increase, whereas the low numbers of publications applying ADLs, UML, or XML-based techniques emphasize the trend towards novel and specific modeling languages for Industry 4.0 .

Considering the different venues relevant to publishing on modeling for Industry 4.0, it is notable that no publications of the International Journal of Production Research or the Transactions on Industrial Informatics were included in the dataset until April 2017. 


\subsection{Different Perspectives on Modeling}

In line with our findings of standardization activities, the identified publication venues also indicate a gap between the different modeling communities (automation engineering, software engineering, etc.) related to Industry 4.0. From our experience, this also is visible in some of the topics relevant to modeling in Industry 4.0, such as 3D modeling, knowledge representation, or simulation that seem to attract fewer publications in the software engineering modeling community (e.g., the MODELS or ECMFA conferences). This also is reified by the different standardization or specification bodies of the different communities. While the OMG considers automation engineering standards, as well as software engineering standards, or cross-cutting standards (e.g., on environment, safety, or quality), there are modeling-related standards by standardization bodies not primarily considering software engineering, such as the Core Manufacturing Simulation Data (CMSD) standardized by SISO (SISOSTD-008) or the related standards by IEC (e.g., IEC 61630 or IEC 62424).

Moreover, there are various standards addressing issues relevant to the software engineering modeling community, such as (1) the standard for the "exchange of product model data" ("STEP" [122]) reified in ISO 10303, which comprises the EXPRESS [122] modeling language, the standard data access interface, or the STEP-NC [160] machine tool control language; (2) the standard for "industrial automation systems and integration - Parts library" ("PLIB") reified in ISO 13569, which defines the OntoML ontology markup language; or the (3) the process specification language of ISO 18629. Hence, we suggest for software engineering researchers to consider these standards when contributing to modeling in Industry 4.0.

Moreover, with AutomationML [15], research and industry have started a promising initiative on modeling automation systems for Industry 4.0 that features research groups for all participating communities. However, the underlying technologies that define models and languages (e.g., XML) can significantly improve from research conducted in the community around model-driven software development.

We also found that research on modeling languages for Industry 4.0 to a large extent addresses challenges either typical to software and systems engineering, such as digital system representation and integration, or typical to artificial intelligence, such as representing knowledge about processes and resources and reasoning about these ( $c f$. Figure 6). Despite these challenges being central to computer science research, the most popular venues ( $c f$. Section 4.5) suggest that this research is not discussed in computer science, but in journals and conferences related to automation engineering instead. Whether this is due to the contributing researchers' backgrounds is subject to ongoing research and cannot be answered from the data on contributing institutions alone (cf. Section 4.4).

Research on modeling languages for Industry 4.0 focuses on constructive contributions, i.e., methods solving specific problems ( $c f$. Section 4.2), while there are few experience reports, validation research, or evaluation papers. 
Similarly, metrics and analyses, expected to be prominent for such a businessdriven research agenda, are very rare. This is in line with the observation that only a few papers conduct empirical evaluations in industrial settings (5.64 \%) and might suggest that the majority of solutions provided to the field are not mature enough for to be evaluated in the field, or that there is a significant amount of research not targeted at industrial needs. Also, there is a noticeable lack of vision papers on modeling for the newly coined research agenda of Industry 4.0, which might contrast the hypothesis that research on modeling for Industry 4.0 is of insufficient maturity.

\subsection{Looking Ahead on Modeling for Industry 4.0}

We are currently striving for new opportunities, but at the same time facing a dramatically increasing complexity in the development and operation of systems with the emergence of Cyber-Physical Production Systems (CPPS) [153] in Industry 4.0. This demands for more comprehensive and systematic views on all aspects of systems (e.g., mechanics, electronics, software, and network) not only in the engineering process but in the operation process as well [23]. Moreover, flexible approaches are needed to adapt the systems' behavior to ever-changing requirements and tasks, unexpected conditions, as well as structural transformations [87]. Modeling languages are traditionally more focused on the development phases as also indicated by our literature study. However, the reference architecture of Industry 4.0 explicitly targets the management of the complete lifecycle, going from development (i.e., type level) to operation (i.e., instance level) in addition to vertical and horizontal integration requirements. In this context, the later phases of the lifecycle may become a new playground for existing modeling languages. Although some of the surveyed languages already provide some support for type and instance level such as UML, typically the instance level modeling did not receive much attention compared to the type level.

To tackle the challenges of Industry 4.0, such as the flexible and resilient adaption of CPPS to changing requirements, the operation processes of CPPS, as well as their interplay with the engineering processes and vice verse, has to be taken into consideration also by the employed modeling languages. This raises the question of how model-based DevOps practices for CPPS can be achieved. Such practices are currently highly needed to reduce the time between identifying the necessity for a change and putting the appropriate change into production. Definitely, we have to go beyond the current support offered by current Product Lifecycle Management (PLM) tools [1].

Furthermore, current DevOps practices have to be completed to be applicable not only for code-based artifacts but for a larger variety of artifacts such as models, engineering documents, CAD drawings, simulation data, etc.

In the following, we present a vision for model-based DevOps as well as challenges related to the development of the next-generation modeling languages that have to be tackled to realize model-based DevOps for Industry 


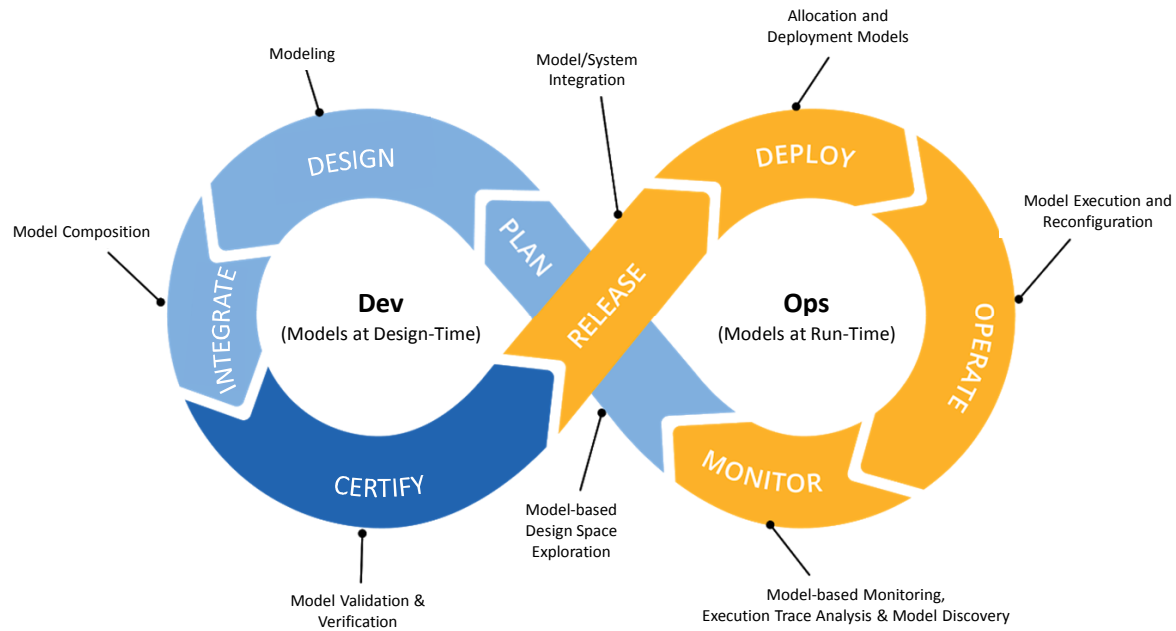

Fig. 15 A vision of model-based DevOps that aims to facilitate addressing the challenges of the CPPS of Industry 4.0 through pervasive modeling across their complete lifecycle.

4.0. Finally, we conclude with the potential benefits of model-based DevOps but also enumerate potential barriers to model-based DevOps.

\subsubsection{Model-Based DevOps: A Vision}

While current DevOps practices apply to code integration, deployment and delivery, we envision the application of the very same practices at the model level. In such a vision, the various domain-specific development models are seamlessly integrated with operations, either models at runtime (e.g., model-based MAPE-K loop or digital twins) or a combination of software and hardware components within a given environment. In the last two decades, the MDE community developed a rich and useful toolset for implementing such a vision through the efficient development, usage, maintenance, and evolution of modeling languages. Figure 15 presents some of the modeling techniques that can be used across the DevOps cycle.

\subsubsection{Model-Based DevOps: What is Needed from Modeling Language} Research?

Integration of the MDE Technologies with DevOps Technologies: In the past decade, a plethora of different modeling languages for design, validation, verification, evolution, and transformation of models have been proposed. However, how these languages may be bundled into a pipeline for continuously integrating, building, testing, and deploying models into production environments is less explored. The only exception is the work by García and Cabot [51] who married continuous deployment technologies and modeldriven technologies. Some approaches towards leveraging MDE in the con- 
text of PLM that might serve as a vantage point for moving from PLM with MDE to model-based DevOps include model- and standards-based data integration [102], increasing virtualization [3,31], or domain-specific languages tailored to the industry's processes [106].

Integration of Different Artifact Kinds: While current model-based technologies provide common services for model-based artifacts, other artifact kinds such as software components or hardware descriptions cannot be directly integrated with models. However, this demands integration techniques on the language level that support a progressive integration of models starting in the engineering process and extending into the deployment process even going to the operation processes. Activities in this direction include, e.g., integrating geometric tolerance information into STEP (ISO 10303) [134] or integrated representations of products, processes, and resources [11] to model system changes over its lifecycle.

Aligning Operational Data and Design Models: A major challenge is the back-propagation of operational data (e.g., measures about performance, energy consumption, masses, costs, etc.) into the documentation provided on top of heterogeneous design models - which may be software engineering models, formal models of physical processes, knowledge bases, CAD, or something else. Currently, most of the modeling languages identified in our study lack a dedicated viewpoint for operations. Extensions to these languages are required to link to operational data or to store summaries of operational data in models (cf. $[54,124])$.

Visualizing Operational Data in Design Models: Operational data is becoming huge in size for complex systems. Even if operational data is aligned with design models, current modeling languages most often fail short in visualization support for non-2D-diagram-based data. Additional requirements for visualization of design models occur such as how to visualize the underlying quality of the data such as uncertainties. Integrating sophisticated visualization techniques [5] are required to provide an understanding of operationenriched design models.

Exploiting Runtime Models for Continuous Improvement of Design Models: Runtime models have gained considerable attention in MDE, mostly in the context of self-* systems. Interpreting runtime models for continuous improvement of the design models (possibly through additional predictive models) would enable reasoning about the next versions of a system. Runtime models would indeed be very helpful here: for instance, assume the transform of the runtime models back into traces which can be replayed by simulators for animation, exploration, etc., on the design models. We, however, found that most publications focus on modeling languages to describe design-time models or runtime data is analyzed without a deeper connection to the design models.

\subsubsection{Perspectives of Model-Based DevOps for Industry 4.0}

The path towards model-based DevOps for Industry 4.0 yields specific benefits and challenges. For instance, considering business concerns, as presented in 
the BizDevOps approach [58], requires reasoning over the global system at the business level - the highest vertical level in the reference architecture of Industry 4.0. This level would benefit from the application of the DevOps principles at the model level as models are closer to the application domain and can provide a comprehensive representation of the system, including its environment and possible extra-functional properties related to business concerns.

Moreover, promoting DevOps principles at the model level enables leveraging it earlier in the development process. Hence, DevOps principles would not only apply to the integration, deployment, delivery, and operation of the global system, but could also apply at a finer level of granularity for the different concerns addressed during the development processes of plants, production systems, and products their various abstraction levels. This could lead to powerful development processes where automation and continuous feedback are not only available at the level of the global system, but also at the level of the different concerns and across the various levels of abstraction. This, for instance, could facilitate operating (partly) virtual factories [29,75] earlier and support factory and CPPS integration planning as well as simulation of manufacturing novel products.

Based on our findings, obstacles to the adoption of model-driven DevOps in Industry 4.0 might arise from a gap between the modeling communities of Industry 4.0 and software engineering. As DevOps is a set of software engineering practices, it largely focuses on cyber (i.e., software) elements, a DevOps for Industry 4.0 must also incorporate its physical parts ( $c f$. Section 4.2) and leverage associated modeling languages. Where DevOps, i.e., introducing change, for pure software elements is manageable, e.g., by over-the-air updates at run-time, changing physical elements at run-time is complicated to impossible. Similarly, software generally can be released and monitored more easily than the physical elements of Industry 4.0. Moreover, a DevOps for Industry 4.0 must comply with relevant industry standards and regulations (see Section 4.3). This is especially critical where (manual) certification prior to deployment is required as this can hamper the DevOps loop. Finally, while modern software engineering tools are providing open APIs to be integrated into DevOps pipelines which allow for automation and traceability, classical PLM tools for managing the lifecycle of physical components by virtual representations are often closed environments with proprietary data formats.

To sum up, with both communities generally leveraging different modeling techniques, standards, and tools, realizing DevOps for Industry 4.0 demands for concentrated efforts to bridge this gap. Otherwise, realizing the reference architecture of Industry 4.0 becomes a utopia.

\section{Threats to Validity}

For identifying the threats to the validity of our SMS, we follow the four basic types of validity threats according to Wohlin et al. [157]. Our study is subject to threats to construct validity (research design), internal validity 
(data extraction), and conclusion validity (reliability). Threats to external validity (generalizability) are irrelevant as the results of this study can neither be generalized to problems domains other than Industry 4.0 nor to solution domains other than modeling.

Regarding threats to research design, the presented findings are valid only for our sample of papers. Hence, it is crucial to ensure the inclusion of as many relevant papers as possible. To achieve this, we included the Google Scholar digital library and only very carefully excluded publications. We are aware that a great number of subsequent exclusions for formal reasons (e.g., non-peer-reviewed materials) are due to querying Google Scholar. However, its inclusion was useful to capture venues not published in the other libraries. Overall, using Google Scholar led to including 207 papers that would have otherwise been omitted.

Moreover, we did not restrict our search to publications mentioning "Industry 4.0" explicitly, but also included the related terms of the search clause's first disjunction. Similarly, the search clause's second disjunction included terms closely related to modeling, without narrowing it to the exact terms. Instead, we used terms one can expect from relevant contributions to be included in the full text. This enabled capturing related publications without focusing on the very specific, partly ambiguous, modeling terminology. Our search clause also might entail a bias towards European research by explicitly mentioning "Industry 4.0", i.e., the name of a European initiative on smart manufacturing, whereas the names of other national initiatives (e.g., the Japanese "Industrial Value Chain" or the "Advanced Manufacturing Initiative" of the United States) are not part of the search clause.

Another threat to research design validity arises from the definition of the criteria of inclusion and exclusion. During the screening, only title, abstract, and keywords were considered. To prevent excluding relevant publications based on the lack of investigation, we included papers we were uncertain of temporarily. In the subsequent classification phase, the complete papers were read and inclusion or exclusion were decided ultimately.

Of course, our mapping study also is subject to the so-called publication bias, i.e., it can report on published results only. As publications focus on positive results, we cannot derive which modeling languages are not applicable from our data sources. Also, we restrict our research to work applied to Industry 4.0, instead of also considering potential applications to it. Due to its diversity, a study on the latter must include at least publications focusing on robotics, the Internet of Things, production planning, enterprise systems, human-computer interaction, and much more. However, including all these fields would dilute the validity of such a study.

Threats to conclusion validity arise drawing wrong conclusions and from the study's replicability. Regarding the former, we have discussed various issues that could lead to wrong conclusions in the context of threats to internal validity. For replicability, we detailed the complete research method in Section 3, which enables replicating every phase of this mapping study. Regarding some conclusions, such as the most active institutions or most relevant journals, our 
study is by construction biased towards institutions and journals publishing in English.

\section{Conclusion}

We conducted a systematic mapping study to investigate the state of research on modeling languages for Industry 4.0. The study revealed that digital representation of cyber-physical production systems, i.e., their interfaces and data models, as well as their integration and (re-)configuration are the prime Industry 4.0 concerns addressed through modeling languages.

The number of papers explicating the authors' expectations of applying modeling languages to Industry 4.0 is rather small. There also are no papers or benchmarks that investigate evaluating the expected benefits through experiments. This is in line with uncovering a lack of experience papers and experience reports. Moreover, there appears little published research on metrics and benchmarks to test the explicated expectations. This might hint that research on modeling languages for Industry 4.0 is still focusing on foundational challenges and maturing the discipline could produce these necessary validations. This also is indicated by the high number of publications focusing on methods and solutions, instead of validation research. Where evaluation research is reported, it mostly focuses on case studies or lab-sized systems at universities possibly using industrial components. To fully investigate the benefits of modeling on Industry 4.0, more evaluation research in industrial settings is necessary.

It is also startling that - despite the huge costs that production system failures might entail - there is relatively little research on validation \& verification. However, with Industry 4.0 being business-driven and aiming to reduce cost and time, such contributions might arise once the field has matured more. Recent trends indicate that validation \& verification already are becoming a more important concern for the field.

We found that domain-specific languages and UML (including variants) are the modeling languages applied most often, followed by knowledge representation techniques. The use of metamodeling and DSLs, as well as UML profiles or other extension mechanisms, might suggest that specific challenges are not supported by current modeling languages. However, in the 23 publications reporting an industrial evaluation of their contributions, this assumption is not reflected. As expected, these publications report on applying more established modeling languages, such as AutomationML ( $c f$. [41]), OWL (cf. [131,139, $141])$, or UML ( $c f .[121,131])$. Nonetheless, even among the publications with industrial evaluation, we found contributions introducing novel metamodels (cf. [71]) or extensions of established ontologies (cf. [113]).

Also, with the majority $76 \%$ of contributions related to DSLs being published since 2014 - and in an increasing number since then - we expect more research contributing modeling techniques specifically tailored to Industry 4.0 in the future. The significantly growing number of papers related to meta- 
modeling and DSLs in the last year alone suggests that the community on modeling for Industry 4.0 invests increasing efforts in tailoring specific modeling tools. This matches the number of modeling standards and extensions to these standards as well. Most notably, Computer Aided Engineering Exchange (CAEX) [16] acts as a modeling language and metamodeling language which is used by AutomationML [42] and enables its extension with domain-specific concepts.

While integration still is a major challenge in Industry 4.0, there seem to be trends to shift research from a mostly digital representation of CPPS towards information management and process modeling. Moreover, research shifts away from applying established (e.g., UML-based) modeling techniques towards specific and tailored modeling techniques. The latter might be an effect of increasing adoption of modeling standards (such as ISO 10303 or IEC 62264) specific to Industry 4.0, which are worthwhile to investigate for everybody aiming to contribute to the field.

Especially modeling knowledge about processes operating on established digital representations seems to become increasingly important. To this end, integration of software engineering and knowledge representation (e.g., on the integration of ontologies and class diagrams or SPARQL and OCL) demands further research that supports its deployment in the Industry 4.0 field. Moreover, there also is less research on modeling for (smart) products of Industry 4.0 than expected.

Future work on investigating the contribution of modeling languages to Industry 4.0 should investigate details on the modeling techniques applied to Industry 4.0, such as their forms, integration, and usage. The dataset produced through our systematic mapping study enables this.

\section{Acknowledgement}

This work has been partially supported by the Austrian Federal Ministry for Digital and Economic Affairs, the National Foundation for Research, Technology and Development and by the FWF in the Project LEA-xDSML under the Grant Number P 30525-N31.

\section{References}

1. Abramovici, M.: Future trends in product lifecycle management (plm). In: The future of product development, pp. 665-674. Springer (2007)

2. The U.S. Advanced Manufacturing Initiative. https://www.nist.gov/sites/ default/files/documents/2017/04/28/Molnar_091211.pdf. Accessed: 201806-06

3. Affonso, R.C., Cheutet, V., Ayadi, M., Haddar, M.: Simulation in product lifecycle: Towards a better information management for design projects. The Journal of Modern Project Management 1(1) (2012)

4. Agner, L.T.W., Soares, I.W., Stadzisz, P.C., SimãO, J.M.: A Brazilian survey on UML and model-driven practices for embedded software development. Journal of Systems and Software 86(4), 997-1005 (2013) 
5. Aigner, W., Miksch, S., Schumann, H., Tominski, C.: Visualization of Time-Oriented Data. Human-Computer Interaction Series. Springer (2011)

6. Al-Fedaghi, S., Al-Shahin, F.: Control software modeling in production systems. The Open Automation and Control Systems Journal 7(1) (2015)

7. Aleksić, D.S., Janković, D.S., Stoimenov, L.V.: A case study on the object-oriented framework for modeling product families with the dominant variation of the topology in the one-of-a-kind production. The International Journal of Advanced Manufacturing Technology 59(1), 397-412 (2012)

8. Alenazi, M., Niu, N., Wang, W., Gupta, A.: Traceability for Automated Production Systems: A Position Paper. In: 2017 IEEE 25th International Requirements Engineering Conference Workshops (REW), pp. 51-55. IEEE (2017)

9. Alexopoulos, K., Makris, S., Xanthakis, V., Sipsas, K., Chryssolouris, G.: A concept for context-aware computing in manufacturing: the white goods case. International Journal of Computer Integrated Manufacturing 29(8), 839-849 (2016)

10. Back, M.G., Lee, D.K., Shin, J.G., Woo, J.H.: A study for production simulation model generation system based on data model at a shipyard. International Journal of Naval Architecture and Ocean Engineering 8(5), 496-510 (2016)

11. Backhaus, J., Reinhart, G.: Digital description of products, processes and resources for task-oriented programming of assembly systems. Journal of Intelligent Manufacturing 28(8), 1787-1800 (2017)

12. Bailey, J., Budgen, D., Turner, M., Kitchenham, B., Brereton, P., Linkman, S.: Evidence Relating to Object-Oriented Software Design: A Survey. In: Proceedings of the First International Symposium on Empirical Software Engineering and Measurement, ESEM '07, pp. 482-484. IEEE Computer Society, Washington, DC, USA (2007)

13. Bareiß, P., Schütz, D., Priego, R., Marcos, M., Vogel-Heuser, B.: A model-based failure recovery approach for automated production systems combining sysml and industrial standards. In: Emerging Technologies and Factory Automation (ETFA), 2016 IEEE 21st International Conference on, pp. 1-7. IEEE (2016)

14. Beecham, S., Baddoo, N., Hall, T., Robinson, H., Sharp, H.: Motivation in Software Engineering: A systematic literature review. Information and software technology 50(9-10), 860-878 (2008)

15. Berardinelli, L., Biffl, S., Lüder, A., Mätzler, E., Mayerhofer, T., Wimmer, M., Wolny, S.: Cross-disciplinary engineering with AutomationML and SysML. atAutomatisierungstechnik 64(4), 253-269 (2016)

16. Berardinelli, L., Drath, R., Maetzler, E., Wimmer, M.: On the evolution of CAEX: A language engineering perspective. In: Emerging Technologies and Factory Automation (ETFA), 2016 IEEE 21st International Conference on, pp. 1-8. IEEE (2016)

17. Bergert, M., Diedrich, C., Kiefer, J., Bar, T.: Automated PLC software generation based on standardized digital process information. In: Emerging Technologies and Factory Automation, 2007. ETFA. IEEE Conference on, pp. 352-359. IEEE (2007)

18. Bergmann, S., Strassburger, S.: Challenges for the Automatic Generation of Simulation Models for Production Systems. In: Proceedings of the 2010 Summer Computer Simulation Conference, SCSC '10, pp. 545-549. Society for Computer Simulation International, San Diego, CA, USA (2010)

19. Bergmann, S., Straßburger, S.: On the use of the Core Manufacturing Simulation Data (CMSD) standard: experiences and recommendations. In: Fall Simulation Interoperability Workshop 2015 (SIW) (2015)

20. Berndt, O., von Lukas, U.F., Kuijper, A.: Functional Modelling And Simulation Of Overall System Ship-Virtual Methods For Engineering And Commissioning In Shipbuilding. In: ECMS, pp. 347-353 (2015)

21. Bigvand, P.G., Drath, R., Scholz, A., Schüller, A.: Agile standardization by means of PCE Requests. In: Emerging Technologies \& Factory Automation (ETFA), 2015 IEEE 20th Conference on, pp. 1-8. IEEE (2015)

22. Boeker, M., Vach, W., Motschall, E.: Google Scholar as replacement for systematic literature searches: good relative recall and precision are not enough. BMC medical research methodology 13(1), 131 (2013)

23. Broy, M., Schmidt, A.: Challenges in engineering cyber-physical systems. Computer $\mathbf{4 7}(2), 70-72(2014)$ 
24. Budgen, D., Brereton, P.: Performing systematic literature reviews in software engineering. In: Proceedings of the 28th international conference on Software engineering, pp. 1051-1052. ACM (2006)

25. Budgen, D., Burn, A.J., Brereton, O.P., Kitchenham, B.A., Pretorius, R.: Empirical evidence about the UML: a systematic literature review. Software: Practice and Experience 41(4), 363-392 (2011)

26. Budgen, D., Turner, M., Brereton, P., Kitchenham, B.: Using mapping studies in software engineering. In: Proceedings of PPIG, vol. 8, pp. 195-204. Lancaster University (2008)

27. Bundesministerium für Bildung und Forschung: Zukunftsprojekt Industrie 4.0. https : //www.bmbf.de/de/zukunftsprojekt-industrie-4-0-848.html. Accessed: 2017-04-20

28. Bscher, C., Voet, H., Krunke, M., Burggrf, P., Meisen, T., Jeschke, S.: Semantic Information Modelling for Factory Planning Projects. Procedia CIRP 41, 478 - 483 (2016)

29. Cândea, G., Cândea, C., Radu, C., Terkaj, W., Sacco, M., Suciu, O.: A practical use of the Virtual Factory Framework. In: 14th International Conference on Modern Information Technology in the Innovation Process of the Industrial Enterprises, Budapest, Hungary (2012)

30. Chavarra-Barrientos, D., Batres, R., Wright, P.K., Molina, A.: A methodology to create a sensing, smart and sustainable manufacturing enterprise. International Journal of Production Research 56(1-2), 584-603 (2018)

31. Chen, D., Maffei, A., Ferreirar, J., Akillioglu, H., Khabazzi, M.R., Zhang, X.: A virtual environment for the management and development of cyber-physical manufacturing systems. IFAC-PapersOnLine 48(7), 29-36 (2015)

32. Chen, D., Panfilenko, D.V., Khabbazi, M.R., Sonntag, D.: A model-based approach to qualified process automation for anomaly detection and treatment. In: Emerging Technologies and Factory Automation (ETFA), 2016 IEEE 21st International Conference on, pp. 1-8. IEEE (2016)

33. Chen, L., Ali Babar, M., Ali, N.: Variability management in software product lines: a systematic review. In: Proceedings of the 13th International Software Product Line Conference, pp. 81-90. Carnegie Mellon University (2009)

34. Condori-Fernandez, N., Daneva, M., Sikkel, K., Wieringa, R., Dieste, O., Pastor, O.: A Systematic Mapping Study on Empirical Evaluation of Software Requirements Specifications Techniques. In: Proceedings of the 2009 3rd International Symposium on Empirical Software Engineering and Measurement (2009)

35. Constantinescu, C., Matarazzo, D., Dienes, D., Francalanza, E., Bayer, M.: Modeling of system knowledge for efficient agile manufacturing: Tool evaluation, selection and implementation scenario in smes. Procedia CIRP 25, 246 - 252 (2014). 8th International Conference on Digital Enterprise Technology - DET 2014 Disruptive Innovation in Manufacturing Engineering towards the 4th Industrial Revolution

36. Constantinescu, C., Matarazzo, D., Dienes, D., Francalanza, E., Bayer, M.: Modeling of system knowledge for efficient agile manufacturing: Tool evaluation, selection and implementation scenario in SMEs. Procedia CIRP 25, 246-252 (2014)

37. Deane, P.M.: The first industrial revolution. Cambridge University Press (1979)

38. Dias Neto, A.C., Subramanyan, R., Vieira, M., Travassos, G.H.: A survey on modelbased testing approaches: a systematic review. In: Proceedings of the 1st ACM international workshop on Empirical assessment of software engineering languages and technologies: held in conjunction with the 22nd IEEE/ACM International Conference on Automated Software Engineering (ASE) 2007, pp. 31-36. ACM (2007)

39. Díaz-Madroñero, M., Mula, J., Peidro, D.: A mathematical programming model for integrating production and procurement transport decisions. Applied Mathematical Modelling 52, 527-543 (2017)

40. Divoux, T., Rondeau, E., Lepage, F.: Using the EXPRESS language as a reference interface to define MMS communication. Journal of Intelligent Manufacturing 8(1), 59-66 (1997)

41. Dorofeev, K., Cheng, C.H., Guedes, M., Ferreira, P., Profanter, S., Zoitl, A.: Device adapter concept towards enabling plug\&produce production environments. In: 2017 
22nd IEEE International Conference on Emerging Technologies and Factory Automation (ETFA), pp. 1-8. IEEE (2017)

42. Drath, R., Luder, A., Peschke, J., Hundt, L.: AutomationML - the glue for seamless automation engineering. In: Emerging Technologies and Factory Automation, 2008. ETFA 2008. IEEE International Conference on, pp. 616-623. IEEE (2008)

43. Dregger, J., Niehaus, J., Ittermann, P., Hirsch-Kreinsen, H., ten Hompel, M.: The digitization of manufacturing and its societal challenges: a framework for the future of industrial labor. In: 2016 IEEE International Symposium on Ethics in Engineering, Science and Technology (ETHICS), pp. 1-3 (2016)

44. Du, J., He, Q., Fan, X.: Automating generation of the assembly line models in aircraft manufacturing simulation. In: Assembly and Manufacturing (ISAM), 2013 IEEE International Symposium on, pp. 155-159. IEEE (2013)

45. Efendioglu, N., Woitsch, R.: A Modelling Method for Digital Service Design and Intellectual Property Management Towards Industry 4.0: CAxMan Case. In: International Conference on Serviceology, pp. 153-163. Springer (2017)

46. Engström, E., Runeson, P.: Software Product Line Testing - A Systematic Mapping Study. Inf. Softw. Technol. 53(1), 2-13 (2011)

47. Engström, E., Runeson, P.: Software product line testing-a systematic mapping study. Information and Software Technology 53(1), 2-13 (2011)

48. Feldmann, S., Herzig, S.J., Kernschmidt, K., Wolfenstetter, T., Kammerl, D., Qamar, A., Lindemann, U., Krcmar, H., Paredis, C.J., Vogel-Heuser, B.: Towards effective management of inconsistencies in model-based engineering of automated production systems. IFAC-PapersOnLine 48(3), 916-923 (2015)

49. Foradis, T., Thramboulidis, K.: From Mechatronic Components to Industrial Automation Things-An IoT model for cyber-physical manufacturing systems. Journal of Software Engineering and Applications 10(08), 734 (2017)

50. Francalanza, E., Borg, J., Constantinescu, C.: A knowledge-based tool for designing cyber physical production systems. Computers in Industry 84, 39-58 (2017)

51. García, J., Cabot, J.: Stepwise adoption of continuous delivery in model-driven engineering. In: DEVOPS (2018)

52. García, M.V., Irisarri, E., Pérez, F., Estévez, E., Marcos, M.: OPC-UA communications integration using a CPPS architecture. In: Ecuador Technical Chapters Meeting (ETCM), IEEE, vol. 1, pp. 1-6. IEEE (2016)

53. García-Borgoñon, L., Barcelona, M., García-García, J., Alba, M., Escalona, M.J.: Software process modeling languages: A systematic literature review. Information and Software Technology 56(2), 103-116 (2014)

54. Gisbert, J.R., Palau, C., Uriarte, M., Prieto, G., Palazón, J.A., Esteve, M., López, O., Correas, J., Lucas-Estañ, M.C., Giménez, P., et al.: Integrated system for control and monitoring industrial wireless networks for labor risk prevention. Journal of Network and Computer Applications 39, 233-252 (2014)

55. Givehchi, O., Landsdorf, K., Simoens, P., Colombo, A.W.: Interoperability for industrial cyber-physical systems: An approach for legacy systems. IEEE Transactions on Industrial Informatics 13(6), 3370-3378 (2017)

56. Göring, M., Fay, A.: Automation systemsformal modeling of temporal change of physical structure. In: IECON 2012-38th Annual Conference on IEEE Industrial Electronics Society, pp. 6160-6165. IEEE (2012)

57. Gregor, M., Hromada, J., Matuszek, J.: Digital Factory supported by simulation and metamodelling. Applied Computer Science 4 (2008)

58. Gruhn, V., Schäfer, C.: Bizdevops: because devops is not the end of the story. In: International Conference on Intelligent Software Methodologies, Tools, and Techniques, pp. 388-398. Springer (2015)

59. Hall, T., Beecham, S., Bowes, D., Gray, D., Counsell, S.: A systematic literature review on fault prediction performance in software engineering. IEEE Transactions on Software Engineering 38(6), 1276-1304 (2012)

60. Harcuba, O., Vrba, P.: Ontologies for flexible production systems. In: Emerging Technologies \& Factory Automation (ETFA), 2015 IEEE 20th Conference on, pp. 1-8. IEEE (2015) 
61. Hasan, B., Wikander, J.: A review On Utilizing Ontological Approaches in Integrating Assembly Design and Assembly Process Planning. International Journal of Mechanical Engineering (SSRG-IJME) 4(11), 5-16 (2017)

62. Heineck, T., Gonçalves, E., Sousa, A., Oliveira, M., Castro, J.: Model-Driven Development in Robotics Domain: A Systematic Literature Review. In: Software Components, Architectures and Reuse (SBCARS), 2016 X Brazilian Symposium on, pp. 151-160. IEEE (2016)

63. Hermann, M., Pentek, T., Otto, B.: Design principles for Industrie 4.0 scenarios. In: System Sciences (HICSS), 2016 49th Hawaii International Conference on, pp. 39283937. IEEE (2016)

64. Hermann, M., Pentek, T., Otto, B.: Design Principles for Industrie 4.0 Scenarios. In: Proceedings of the 2016 49th Hawaii International Conference on System Sciences (HICSS), HICSS '16, pp. 3928-3937. IEEE Computer Society, Washington, DC, USA (2016)

65. High Value Manufacturing Carapult. https://hvm. catapult.org.uk/. Accessed: 2018-06-05

66. Hildebrandt, C., Glawe, M., Müller, A.W., Fay, A.: Reasoning on Engineering Knowledge: Applications and Desired Features. In: European Semantic Web Conference, pp. 65-78. Springer (2017)

67. Hoffmann, A., Angerer, A., Schierl, A., Vistein, M., Reif, W.: Service-oriented robotics manufacturing by reasoning about the scene graph of a robotics cell. In: ISR/Robotik 2014; 41st International Symposium on Robotics; Proceedings of, pp. 1-8. VDE (2014)

68. Holz, D., Topalidou-Kyniazopoulou, A., Rovida, F., Pedersen, M.R., Krüger, V., Behnke, S.: A skill-based system for object perception and manipulation for automating kitting tasks. In: Emerging Technologies \& Factory Automation (ETFA), 2015 IEEE 20th Conference on, pp. 1-9. IEEE (2015)

69. Hummel, B., Braun, P.: Towards an integrated system model for testing and verification of automation machines. In: Proceedings of the 2008 International Workshop on Models in Software Engineering, MiSE '08, pp. 51-56. ACM, New York, NY, USA (2008)

70. The Industrial Value Chain Initiative. https://iv-i.org/wp/en/about-us/ whatsivi/. Accessed: 2018-06-04

71. Irisarri, E., García, M.V., Pérez, F., Estévez, E., Marcos, M.: A model-based approach for process monitoring in oil production industry. In: Emerging Technologies and Factory Automation (ETFA), 2016 IEEE 21st International Conference on, pp. 1-4. IEEE (2016)

72. Jorgensen, M., Shepperd, M.: A Systematic Review of Software Development Cost Estimation Studies. IEEE Trans. Softw. Eng. 33(1), 33-53 (2007)

73. Jung, K., Kulvatunyou, B., Choi, S., Brundage, M.P.: An overview of a smart manufacturing system readiness assessment. In: IFIP International Conference on Advances in Production Management Systems, pp. 705-712. Springer (2016)

74. Juristo, N., Moreno, A.M., Vegas, S., Solari, M.: In Search of What We Experimentally Know about Unit Testing. IEEE Software 23(6), 72-80 (2006)

75. Kádár, B., Terkaj, W., Sacco, M.: Semantic Virtual Factory supporting interoperable modelling and evaluation of production systems. CIRP Annals-Manufacturing Technology 62(1), 443-446 (2013)

76. Kannengiesser, U., Müller, H.: Towards agent-based smart factories: A subject-oriented modeling approach. In: Web Intelligence (WI) and Intelligent Agent Technologies (IAT), 2013 IEEE/WIC/ACM International Joint Conferences on, vol. 3, pp. 83-86. IEEE (2013)

77. Keele, S.: Guidelines for performing systematic literature reviews in software engineering (2007)

78. Kern, H., Stefan, F., Dimitrieski, V.: Intelligent and self-adapting integration between machines and information systems. IADIS International Journal on Computer Science \& Information Systems 10(1) (2015)

79. Khaleel, H., Conzon, D., Kasinathan, P., Brizzi, P., Pastrone, C., Pramudianto, F., Eisenhauer, M., Cultrona, P.A., Rusinà, F., Lukáč, G., et al.: Heterogeneous applications, tools, and methodologies in the car manufacturing industry through an iot approach. IEEE Systems journal 11(3), 1412-1423 (2017) 
80. Khan, A., Turowski, K.: A Survey of Current Challenges in Manufacturing Industry and Preparation for Industry 4.0. In: Proceedings of the First International Scientific Conference on Intelligent Information Technologies for Industry (IITI'16), pp. 15-26 (2016). DOI 10.1007/978-3-319-33609-1_2

81. Kitchenham, B., Brereton, O.P., Budgen, D., Turner, M., Bailey, J., Linkman, S.: Systematic literature reviews in software engineering a systematic literature review. Information and Software Technology 51(1), 7 - 15 (2009). Special Section - Most Cited Articles in 2002 and Regular Research Papers

82. Kitchenham, B.A., Budgen, D., Brereton, O.P.: The Value of Mapping Studies: A Participant-Observer Case Study. In: Proceedings of the 14th International Conference on Evaluation and Assessment in Software Engineering, EASE'10, pp. 25-33. BCS Learning \& Development Ltd., Swindon, UK (2010)

83. Kosar, T., Bohra, S., Mernik, M.: Domain-specific languages: A systematic mapping study. Information and Software Technology 71, 77-91 (2016)

84. Kovalenko, O., Wimmer, M., Sabou, M., Lüder, A., Ekaputra, F.J., Biff, S.: Modeling AutomationML: Semantic web technologies vs. model-driven engineering. In: Emerging Technologies \& Factory Automation (ETFA), 2015 IEEE 20th Conference on, pp. 1-4. IEEE (2015)

85. Laguna, M.A., Crespo, Y.: A Systematic Mapping Study on Software Product Line Evolution: From Legacy System Reengineering to Product Line Refactoring. Sci. Comput. Program. 78(8), 1010-1034 (2013)

86. Lahire, P., Parigot, D., Tundrea, E.: SMARTFACTORY - an Implementation of the Domain Driven Development Approach. In: SACI2004, 1st Romanian-Hungarian Joint Symposium on Applied Computational Intelligence, p. 6 (2004)

87. Lee, E.A.: Cyber Physical Systems: Design Challenges. In: Proceedings of the 11th IEEE International Symposium on Object-Oriented Real-Time Distributed Computing (ISORC), pp. 363-369 (2008)

88. Liao, Y., Deschamps, F., de Freitas Rocha Loures, E., Ramos, L.F.P.: Past, present and future of industry 4.0 - a systematic literature review and research agenda proposal. International Journal of Production Research 55(12), 3609-3629 (2017). DOI 10.1080/ 00207543.2017.1308576

89. Liebel, G., Marko, N., Tichy, M., Leitner, A., Hansson, J.: Assessing the state-ofpractice of model-based engineering in the embedded systems domain. In: International Conference on Model Driven Engineering Languages and Systems, pp. 166-182. Springer (2014)

90. Long, F., Zeiler, P., Bertsche, B.: Potentials of coloured petri nets for realistic availability modelling of production systems in Industry 4.0. In: Proceedings of the ESREL 2015 Conference, 07.09.-10.09. 2015, Zürich, Switzerland, pp. 4455-4463 (2015)

91. Loskyll, M., Heck, I., Schlick, J., Schwarz, M.: Context-based orchestration for control of resource-efficient manufacturing processes. Future Internet 4(3), 737-761 (2012)

92. Lu, Y.: Industry 4.0: A survey on technologies, applications and open research issues. Journal of Industrial Information Integration 6, 1-10 (2017)

93. Lütjen, M., Kreowski, H.J., Franke, M., Thoben, K.D., Freitag, M.: Model-driven logistics engineering-challenges of model and object transformation. Procedia Technology 15, 303-312 (2014)

94. Lütjen, M., Rippel, D.: GRAMOSA framework for graphical modelling and simulationbased analysis of complex production processes. The International Journal of Advanced Manufacturing Technology 81(1-4), 171-181 (2015)

95. Ma, Z., Hudic, A., Shaaban, A., Plosz, S.: Security viewpoint in a reference architecture model for cyber-physical production systems. In: Security and Privacy Workshops (EuroS\&PW), 2017 IEEE European Symposium on, pp. 153-159. IEEE (2017)

96. Made in China 2025. https://www.merics.org/sites/default/files/ 2017-09/MPOC_No.2_MadeinChina2025.pdf. Accessed: 2018-06-06

97. Mahdavi-Hezavehi, S., Durelli, V.H., Weyns, D., Avgeriou, P.: A systematic literature review on methods that handle multiple quality attributes in architecture-based selfadaptive systems. Information and Software Technology (2017)

98. Korea - Manufacturing Technology - Smart Factory. https://www.export.gov/ article?id=Korea-Manufacturing-Technology-Smart-Factory. Accessed: 2018-06-04 
99. Matei, M.M., Popescu, D.: Extend IT Services in Process Control Domain for Onshore Oilfields. In: 10th International Conference on Dynamical Systems and Control (CONTROL15), December, pp. 12-14 (2015)

100. Mätzler, S., Wollschlaeger, M.: Interchange format for the generation of functional elements for industrie 4.0 components. In: Industrial Electronics Society, IECON 201743rd Annual Conference of the IEEE, pp. 5453-5459. IEEE (2017)

101. Mazak, A., Huemer, C.: A standards framework for value networks in the context of Industry 4.0. In: Industrial Engineering and Engineering Management (IEEM), 2015 IEEE International Conference on, pp. 1342-1346. IEEE (2015)

102. McMillan, A.J., Swindells, N., Archer, E., McIlhagger, A., Sung, A., Leong, K., Jones, R.: A review of composite product data interoperability and product life-cycle management challenges in the composites industry. Advanced Manufacturing: Polymer \& Composites Science 3(4), 130-147 (2017)

103. Mechs, S., Grimm, S., Beyer, D., Lamparter, S.: Evaluation of prediction accuracy for energy-efficient switching of automation facilities. In: Industrial Electronics Society, IECON 2013-39th Annual Conference of the IEEE, pp. 6928-6933. IEEE (2013)

104. Medvidovic, N., Taylor, R.N.: A Classification and Comparison Framework for Software Architecture Description Languages. IEEE Transactions on Software Engineering (2000)

105. Mehmood, A., Jawawi, D.N.: Aspect-oriented model-driven code generation: A systematic mapping study. Information and Software Technology 55(2), 395 - 411 (2013). Special Section: Component-Based Software Engineering (CBSE), 2011

106. Merkumians, M.M., Baierling, M., Schitter, G.: A service-oriented domain specific language programming approach for batch processes. In: Emerging Technologies and Factory Automation (ETFA), 2016 IEEE 21st International Conference on, pp. 1-9. IEEE (2016)

107. Michaloski, J., Proctor, F., Arinez, J., Berglund, J.: Toward the ideal of automating production optimization. In: ASME 2013 International Mechanical Engineering Congress and Exposition, pp. V02AT02A089-V02AT02A089. American Society of Mechanical Engineers (2013)

108. Miguel Gutierrez-Guerrero, J., Antonio Holgado-Terriza, J.: iMMAS an industrial meta-model for automation system using OPC UA. Elektronika ir Elektrotechnika 23(3), 3-11 (2017)

109. Mokyr, J.: The second industrial revolution, 1870-1914. Storia delleconomia Mondiale pp. 219-45 (1998)

110. Mosterman, P.J., Zander, J.: Cyber-physical Systems Challenges: A Needs Analysis for Collaborating Embedded Software Systems. Softw. Syst. Model. 15(1), 5-16 (2016)

111. do Nascimento, L.M., Viana, D.L., Neto, P.A.S., Martins, D.A., Garcia, V.C., Meira S.R.: A systematic mapping study on domain-specific languages. In: The Seventh International Conference on Software Engineering Advances (ICSEA 2012), pp. 179$187(2012)$

112. Negri, E., Fumagalli, L., Garetti, M., Tanca, L.: Requirements and languages for the semantic representation of manufacturing systems. Computers in Industry 81, 55-66 (2016)

113. Negri, E., Perotti, S., Fumagalli, L., Marchet, G., Garetti, M.: Modelling internal logistics systems through ontologies. Computers in Industry 88, 19-34 (2017)

114. Niggemann, O., Maier, A., Jasperneite, J.: Model-based Development of Automation Systems. In: MBEES, pp. 45-54 (2010)

115. Onori, M., Semere, D., Barata, J.: Evolvable assembly systems: from evaluation to application. In: Innovation in Manufacturing Networks, pp. 205-214. Springer (2008)

116. Pedrazzoli, P., Alge, M., Bettoni, A., Canetta, L.: Modeling and simulation tool for sustainable MC supply chain design and assessment. In: IFIP International Conference on Advances in Production Management Systems, pp. 342-349. Springer (2012)

117. Petersen, K., Feldt, R., Mujtaba, S., Mattsson, M.: Systematic Mapping Studies in Software Engineering. In: EASE, vol. 8, pp. 68-77 (2008)

118. Petrasch, R., Hentschke, R.: Process modeling for Industry 4.0 applications: Towards an Industry 4.0 process modeling language and method. In: Computer Science and Software Engineering (JCSSE), 2016 13th International Joint Conference on, pp. 1-5. IEEE (2016) 
119. Pfouga, A., Stjepandić, J.: Leveraging 3D Geometric Knowledge in the Product Lifecycle based on industrial standards. Journal of Computational Design and Engineering (2017)

120. Pisching, M.A., Junqueira, F., Filho, D.J.S., Miyagi, P.E.: Service Composition in the Cloud-Based Manufacturing Focused on the Industry 4.0, pp. 65-72. Springer International Publishing, Cham (2015). DOI 10.1007/978-3-319-16766-4_7

121. Polacsek, T., Roussel, S., Bouissiere, F., Cuiller, C., Dereux, P.E., Kersuzan, S.: Towards thinking manufacturing and design together: An aeronautical case study. In: International Conference on Conceptual Modeling, pp. 340-353. Springer (2017)

122. Pratt, M.J.: Introduction to ISO 10303the STEP standard for product data exchange. Journal of Computing and Information Science in Engineering 1(1), 102-103 (2001)

123. Pretorius, R., Budgen, D.: A Mapping Study on Empirical Evidence Related to the Models and Forms Used in the UML. In: Proceedings of the Second ACM-IEEE International Symposium on Empirical Software Engineering and Measurement, ESEM '08, pp. 342-344. ACM, New York, NY, USA (2008)

124. Prévost, G., Blech, J.O., Foster, K., Schmidt, H.W.: An architecture for visualization of industrial automation data. In: ENASE, pp. 38-46 (2017)

125. Priego, R., Agirre, A., Estévez, E., Orive, D., Marcos, M.: Middleware-based support for reconfigurable mechatronic systems. IFAC-PapersOnLine 48(10), 81-86 (2015)

126. Ranky, P.G., Lonkar, M., Chamyvelumani, S.: etransition models of collaborating design and manufacturing enterprises. International Journal of Computer Integrated Manufacturing 16(4-5), 255-266 (2003)

127. Rashid, M.A., Qureshi, H., Khan, N.: ERP Life-cycle Management for Aerospace Smart Factory: A Multi-disciplinary Approach. International Journal of Computer Applications 26(11) (2011)

128. Ren, G., Hua, Q., Deng, P., Yang, C., Zhang, J.: A multi-perspective method for analysis of cooperative behaviors among industrial devices of smart factory. IEEE Access 5, 10,882-10,891 (2017)

129. Runde, S., Wolf, G., Braun, M., Siemens, A.: EDDL and semantic webFrom field device integration (FDI) to Future Device Management (FDM). In: Emerging Technologies \& Factory Automation (ETFA), 2013 IEEE 18th Conference on, pp. 1-8. IEEE (2013)

130. Sabou, M., Ekaputra, F., Kovalenko, O., Biffl, S.: Supporting the engineering of cyberphysical production systems with the AutomationML analyzer. In: Cyber-Physical Production Systems (CPPS), 2016 1st International Workshop on, pp. 1-8. IEEE (2016)

131. Sadigh, B.L., Unver, H.O., Nikghadam, S., Dogdu, E., Ozbayoglu, A.M., Kilic, S.E.: An ontology-based multi-agent virtual enterprise system (OMAVE): part 1: domain modelling and rule management. International Journal of Computer Integrated Manufacturing 30(2-3), 320-343 (2017)

132. Sadlauer, A., Hehenberger, P.: Using design languages in model-based mechatronic system design processes. International Journal of Agile Systems and Management 10(1), 73-91 (2017)

133. Saraeian, S., Shirazi, B., Motameni, H.: Towards an extended BPMS prototype: Open challenges of BPM to flexible and robust orchestrate of uncertain processes. Computer Standards \& Interfaces (2017)

134. Sarigecili, M.I., Roy, U., Rachuri, S.: Enriching step product model with geometric dimension and tolerance information for one-dimensional tolerance analysis. Journal of Computing and Information Science in Engineering 17(2), 021,004 (2017)

135. Schneider, M., Mittag, T., Gausemeier, J.: Modeling Language for Value Networks. In: 25th International Association for Management of Technology Conference Proceedings, 25th International Association for Management of Technology Conference, vol. 25, p. 94 110. International Association for Management of Technology (IAMOT), IAMOT, Orlando, Florida (2016)

136. Schubert, D., Heinzemann, C., Gerking, C.: Towards Safe Execution of Reconfigurations in Cyber-Physical Systems. In: Component-Based Software Engineering (CBSE), 2016 19th International ACM SIGSOFT Symposium on, pp. 33-38. IEEE (2016)

137. Sjoberg, D.I.K., Hannay, J.E., Hansen, O., By Kampenes, V., Karahasanovic, A., Liborg, N.K., C. Rekdal, A.: A Survey of Controlled Experiments in Software Engineering. IEEE Trans. Softw. Eng. 31(9), 733-753 (2005) 
138. Soares, A.L., Ferreira, J.P., Mendonça, J.: Organizational behaviour analysis and information technology fitness in manufacturing. In: Balanced Automation Systems, pp. 319-326. Springer (1995)

139. Soylu, A., Kharlamov, E., Zheleznyakov, D., Jimenez-Ruiz, E., Giese, M., Skjæveland, M.G., Hovland, D., Schlatte, R., Brandt, S., Lie, H., et al.: Optiquevqs: a visual query system over ontologies for industry. Semantic Web (Preprint), 1-34 (2018)

140. Steimer, C., Fischer, J., Aurich, J.C.: Model-based design process for the early phases of manufacturing system planning using sysml. Procedia CIRP 60, 163-168 (2017)

141. Steinegger, M., Melik-Merkumians, M., Zajc, J., Schitter, G.: A framework for automatic knowledge-based fault detection in industrial conveyor systems. In: 2017 22nd IEEE International Conference on Emerging Technologies and Factory Automation (ETFA), pp. 1-6. IEEE (2017)

142. Stemmler, S., Reiter, M., Abel, D.: Model predictive control as a module for autonomously running complex plastics production processes. International Polymer Science and Technology 41(12), T1 (2014)

143. Strang, D., Anderl, R.: Assembly process driven component data model in cyberphysical production systems. In: Proceedings of the World Congress on Engineering and Computer Science, vol. 2 (2014)

144. Sungur, C.T., Breitenbücher, U., Leymann, F., Wieland, M.: Context-sensitive adaptive production processes. Procedia CIRP 41, 147-152 (2016)

145. Szvetits, M., Zdun, U.: Systematic literature review of the objectives, techniques, kinds, and architectures of models at runtime. Software \& Systems Modeling 15(1), 31-69 (2016)

146. Takahashi, K., Ogata, Y., Nonaka, Y.: A proposal of unified reference model for smart manufacturing. In: Automation Science and Engineering (CASE), 2017 13th IEEE Conference on, pp. 964-969. IEEE (2017)

147. Thoma, A., Kormann, B., Vogel-Heuser, B.: Fault-centric system modeling using SysML for reliability testing. In: Emerging Technologies \& Factory Automation (ETFA), 2012 IEEE 17th Conference on, pp. 1-8. IEEE (2012)

148. Thomalla, C.S.: Interoperability in manufacturing by semantic integration. In: System Science, Engineering Design and Manufacturing Informatization (ICSEM), 2011 International Conference on, vol. 2, pp. 146-149. IEEE (2011)

149. Thramboulidis, K., Christoulakis, F.: UML4IoT - a UML-based approach to exploit IoT in cyber-physical manufacturing systems. Computers in Industry 82, 259-272 (2016)

150. Torchiano, M., Tomassetti, F., Ricca, F., Tiso, A., Reggio, G.: Relevance, benefits, and problems of software modelling and model driven techniquesA survey in the Italian industry. Journal of Systems and Software 86(8), 2110-2126 (2013)

151. Trappey, A.J.C., Trappey, C.V., Govindarajan, U.H., Sun, J.J., Chuang, A.C.: A Review of Technology Standards and Patent Portfolios for Enabling Cyber-Physical Systems in Advanced Manufacturing. IEEE Access 4, 7356-7382 (2016)

152. Van Stein, B., Van Leeuwen, M., Wang, H., Purr, S., Kreissl, S., Meinhardt, J., Bäck, T.: Towards Data Driven Process Control in Manufacturing Car Body Parts. In: Computational Science and Computational Intelligence (CSCI), 2016 International Conference on, pp. 459-462. IEEE (2016)

153. Vangheluwe, H., Amaral, V., Giese, H., Broenink, J., Schätz, B., Norta, A., Carreira, P. Lukovic, I., Mayerhofer, T., Wimmer, M., Vallecillo, A.: MPM4CPS: Multi-Paradigm Modelling for Cyber-Physical Systems. In: Proceedings of the Project Showcase @ STAF 2015, pp. 1-10 (2016)

154. Vogel-Heuser, B., Hess, D.: Guest Editorial Industry 4.0 - Prerequisites and Visions. IEEE Transactions on Automation Science and Engineering 13(2), 411-413 (2016)

155. Vogel-Heuser, B., Rösch, S., Fischer, J., Simon, T., Ulewicz, S., Folmer, J., et al.: Fault handling in PLC-based industry 4.0 automated production systems as a basis for restart and self-configuration and its evaluation. Journal of Software Engineering and Applications 9(01), 1 (2016)

156. Walch, M.: Knowledge-driven enrichment of cyber-physical systems for industrial applications using the KbR modelling approach. In: Agents (ICA), 2017 IEEE International Conference on, pp. 84-89. IEEE (2017) 
157. Wohlin, C., Runeson, P., Höst, M., Ohlsson, M.C., Regnell, B.: Experimentation in Software Engineering. Springer (2012)

158. Wollert, J., Lehne, M.: Modeling for Ship Design and Production. In: 1991 Ship Production Symposium Proceedings: Building the Ships and Boats of 2010-The Way Forward, p. 1 (1991)

159. Wortmann, A., Combemale, B., Barais, O.: A Systematic Mapping Study on Modeling for Industry 4.0. In: Conference on Model Driven Engineering Languages and Systems (MODELS'17), pp. 281-291. IEEE (2017)

160. Xu, X.: Realization of STEP-NC enabled machining. Robotics and ComputerIntegrated Manufacturing 22(2), 144-153 (2006)

161. Zadeh, N.S., Lindberg, L., El-Khoury, J., Sivard, G.: Service Oriented Integration of Distributed Heterogeneous IT Systems in Production Engineering Using Information Standards and Linked Data. Modelling and Simulation in Engineering 2017 (2017)

162. Zhang, C., Budgen, D.: What Do We Know About the Effectiveness of Software Design Patterns? IEEE Trans. Softw. Eng. 38(5), 1213-1231 (2012)

163. Zhang, Q., Liu, Y., Zhang, Z.: A new method for automatic optimization of drawbead geometry in the sheet metal forming process based on an iterative learning control model. The International Journal of Advanced Manufacturing Technology pp. 1-17 (2016)

164. Zhao, W.B., Park, Y.H., Lee, H.Y., Jun, C.M., Do Noh, S.: Design and implementation of a PLM system for sustainable manufacturing. In: IFIP International Conference on Product Lifecycle Management, pp. 202-212. Springer (2012)

165. Zhiwei, X., Yongxian, L.: Mechanical production line simulation and optimization analysis. In: 2008 IEEE International Conference on Automation and Logistics, pp. 29252930 (2008). DOI 10.1109/ICAL.2008.4636677 